\title{
O ARRANJO PRODUTIVO LOCAL DE PETRÓLEO E GÁS EM MACAÉ: ORIGEM, EVOLUÇÃO, IMPACTOS DA CRISE DO CONTRACHOQUE DE 2014 E PERSPECTIVAS PÓS-CRISE ${ }^{1}$
}

\author{
Romeu e Silva Neto ${ }^{2}$ \\ ORCID: https://orcid.org/0000-0001-7061-8824 \\ Robson Santos Dias 3 \\ ORCID: https://orcid.org/0000-0002-2157-2935
}

Recebido em: 30/07/2021.

Publicado em: 0/09/2021.

\section{RESUMO}

Macaé se tornou, nas últimas décadas, o mais importante e dinâmico polo de crescimento econômico e populacional do interior fluminense, em razão da formidável oferta de empregos formais, muitos dos quais com remuneração mais elevada que a média dos outros municípios do estado. Esse fenômeno deve-se à formação do Arranjo Produtivo Local (APL) de petróleo e gás natural que se concentrou, desde o final da década de 1970, com a instalação da Petrobrás e da estrutura de apoio no município. O arranjo é altamente especializado, sendo liderado pelas atividades de 'extração de petróleo e gás natural' e das 'atividades de apoio à extração de petróleo e gás natural'. Entretanto, com o início da produção de petróleo na Bacia de Santos a partir do início da década de 2010, e com os efeitos do contrachoque do petróleo de 2014, o papel do APL tem passado por mudanças significativas. O presente estudo, de caráter exploratório e descritivo, analisa os impactos desses fatores sobre o APL, com destaque para o Quociente Locacional (QL), sobre a arrecadação de royalties do município, sobre os estabelecimentos e os empregos formais e suas características. Os resultados apontam para impactos negativos sobre a arrecadação e o mercado de trabalho local, especialmente, sobre os empregos de maiores exigências de treinamento técnico especializado de nível médio e superior, e que também eram os que pagavam maiores salários. No entanto, embora com redução do QL, como a crise foi generalizada em nível nacional, as perdas de Macaé não representaram menor centralidade do arranjo produtivo no conjunto das atividades de exploração e produção de petróleo e gás no país. Ainda assim, existe uma série de incertezas com relação à evolução futura do arranjo produtivo que abre novos campos de estudos.

\section{Palavras Chaves:}

arranjo produtivo local; petróleo e gás natural; Macaé; crise do petróleo; mercado de trabalho.

\section{1 (cc) BY-NC-SA}

2021 Silva Neto Et al. Este é um artigo de acesso aberto distribuído sob os termos da Licença Creative Commons BY-NC-SA 4.0, que permite uso, distribuição e reprodução para fins não comercias, com a citação dos autores e da fonte original e sob a mesma licença

2 Professor Titular do IFF - Instituto Federal Fluminense, do PPGE - Programa de Pós-Graduação em Engenharia Ambiental e do Mestrado em Sistemas Aplicados à Engenharia e Gestão (SAEG).

${ }^{3}$ Professor do IFF Cabo Frio - Instituto federal Fluminense. Pesquisador do NEED - Núcleo de Estudos e estratégias e desenvolvimento e do OBPETRO - Observatório Sócioeconômico dos Municípios Produtores de Petróleo do Estado do Rio de Janeiro. 


\title{
ARRANGEMENT PRODUCTION OIL AND GAS IN LOCAL MACAÉ: ORIGIN, EVOLUTION, CRISIS IMPACT OF COUNTERSHOCK 2014 AND PERSPECTIVES POST- CRISIS
}

\begin{abstract}
Macaé has become, in recent decades, the most important and dynamic center of economic and population growth in the interior of the state of Rio de Janeiro, due to the formidable supply of formal jobs, many of which have higher wages than the average of other municipalities in the state. This phenomenon is due to the formation of the Local Productive Arrangement (APL) of oil and natural gas, which has been concentrated since the end of the 1970s, with the installation of Petrobras and the support structure in the municipality. The arrangement is highly specialized, being led by the activities of 'extraction of oil and natural gas' and 'support activities to the extraction of oil and natural gas'. However, with the start of oil production in the Santos Basin from the early 2010s, and the effects of the 2014 oil crisis, the role of the APL has undergone significant changes. This exploratory and descriptive study analyzes the impacts of these factors on APL, especially the Locational Quotient (LQ), on the collection of royalties in the municipality, on establishments and formal jobs, and their characteristics. The results point to negative impacts on tax collection and the local labor market, especially for jobs requiring more specialized technical training at the high school and college levels, and which also paid higher wages. However, although with a reduction in the QL, as the crisis was generalized at the national level, Macaé's losses did not represent less centrality of the productive arrangement in the set of oil and gas exploration and production activities in the country. Still, there is a series of uncertainties regarding the future evolution of the productive arrangement that opens new fields of study.
\end{abstract}

Key Words:

local productive arrangement; oil and natural gas; Macae; oil crisis; job market

\section{L'ARRANGEMENT PRODUCTIF LOCAL DU PÉTROLE ET DU GAZ À MACAÉ: ORIGINE, ÉVOLUTION, IMPACTS DE LA CRISE DU CONTRE-CHOC 2014 ET PERSPECTIVES POST-CRISE}

\section{RÉSUMÉ}

Au cours des dernières décennies, Macaé est devenu le centre le plus important et le plus dynamique de la croissance économique et démographique de l'intérieur de l'État de Rio de Janeiro. Ce phénomène est dû à la formation d'un arrangement productif local (APL) pour le pétrole et le gaz naturel, qui s'est concentré depuis la fin des années 1970, avec l'installation de Petrobras et de sa structure de soutien dans la municipalité. Le dispositif est très spécialisé, avec en tête les activités d'"extraction de pétrole et de gaz naturel" et les "activités de soutien à l'extraction de pétrole et de gaz naturel". Cependant, avec le début de la production pétrolière dans le bassin de Santos à partir du début des années 2010, et avec les effets du contrecoup pétrolier de 2014, le rôle de l'APL a subi des changements importants. Cette étude exploratoire et descriptive analyse les impacts de ces facteurs sur l'APL, notamment le Quotient de localisation (QL), sur la perception des redevances dans la commune, sur les établissements et emplois formels et leurs caractéristiques. Les résultats mettent en évidence des impacts négatifs sur les revenus et le marché du travail local, notamment pour les 
emplois nécessitant une formation technique plus spécialisée aux niveaux du lycée et de l'université, et dont les salaires sont également plus élevés. Cependant, malgré la réduction du NQ, puisque la crise s'est généralisée au niveau national, les pertes de Macaé n'ont pas représenté une moindre centralité de l'arrangement productif dans l'ensemble des activités d'exploration et de production de pétrole et de gaz dans le pays. Cependant, il existe une série d'incertitudes concernant l'évolution future de l'arrangement productif qui ouvre de nouveaux champs d'études.

\section{Mots-clés:}

arrangement productif local ; pétrole et gaz naturel ; Macaé ; crise pétrolière ; marché du travail

\section{INTRODUÇÃO}

O município de Macaé está localizado na Região Norte Fluminense e, junto com Campos dos Goytacazes, suas cidades sedes constituem os principais centros urbanos da região. Por muitos anos, o alicerce da economia de Macaé, que surgiu como cidade em 1846, foi o cultivo da cana-de-açúcar, que respondeu por um crescimento demográfico expressivo nos séculos XVIII e XIX. De acordo com o Tribunal de Contas do Estado do Rio de Janeiro (TCE-RJ, 2020), até o início do século XX, a economia do município se fundamentava na produção da cana-de-açúcar e do café, na pecuária e na extração do pescado. A partir de 1974, com a descoberta de petróleo na região e com a chegada da Petrobras, Macaé passou a viver um novo momento econômico, marcado fundamentalmente pela chegada de diversas empresas na cidade e pelo acelerado crescimento econômico e demográfico.

Em 2010, no último Censo Demográfico (IBGE, 2021), Macaé tinha uma população de 206.728 habitantes, correspondente a 24,3\% do contingente da Região Norte Fluminense. A taxa de urbanização correspondia a $98 \%$ da população. Em comparação com a década anterior, a população do município aumentou 56,1\%, o $4^{\circ}$ maior crescimento no estado, muito em função da migração de pessoas em busca de oportunidades de empregos nas empresas do setor de petróleo e gás instaladas na cidade.

Atualmente, a população estimada para 2020 é de 261.501 habitantes (IBGE, 2021) e a cidade passou a ser conhecida como "a capital nacional do petróleo", em função de, conforme mencionado, sediar empresas do setor de petróleo e gás que exploram a Bacia de Campos. O petróleo passou a ser a maior força econômica de Macaé e a cidade viveu um grande crescimento econômico por ser a base de operações da Petrobras, das outras petroleiras e das para-petroleiras. A cadeia produtiva do petróleo e o crescimento populacional impulsionado por ela, impactaram outros segmentos econômicos como a indústria e os setores de comércio e serviços, incluindo o turismo de negócios, que se fortaleceram com o surgimento de shoppings, hotéis e restaurantes. Junto com o dinamismo da economia do petróleo, o recebimento de royalties e participações especiais aumentou a arrecadação total do município e sua capacidade de investimentos. 
Macaé passou a ser um enclave do arranjo produtivo do petróleo e gás natural. Já em 1985, poucos anos após a primeira produção comercial na Bacia de Campos, Macaé já apresentava elevado Quociente Locacional no subsetor de extração mineral, ultrapassando o índice 40 de concentração.

Em que pese o crescimento econômico, a cidade atraiu milhares de pessoas da região Norte Fluminense e de outras regiões do país, e grande parte dos migrantes não tinham qualificação profissional para encontrar trabalho na competitiva cadeia produtiva do petróleo e gás, gerando um aumento de pobreza nas periferias da cidade. A cidade apresentava bons indicadores de desenvolvimento socioeconômico no ano 2000, ocupando a $4^{\mathrm{a}}$ posição do IDHM (Índice de Desenvolvimento Humano Municipal). Mas foi perdendo posições relativas entre os 92 municípios do estado do Rio de Janeiro. Em 2010, passou a ocupar a $7^{\text {a }}$ posição do IDHM e, em 2016, a $17^{a}$ posição do IFDM (Índice FIRJAN de Desenvolvimento Municipal),

A partir de 2014, a cidade e a região foram acometidas pela crise do contrachoque do petróleo, motivada por fatores como as forças de oferta e demanda da commodity, os fatores geopolíticos, a financeirização do petróleo, as mudanças no marco regulatório do petróleo no país, e a crise política no país que, por sua vez, dentre vários fatores, foi motivada também pela Operação Lava Jato. Tais fatores conjugados influenciaram a crise da Petrobras, das petroleiras e das para-petroleiras, obrigando-as a reduzir seus investimentos e escopos de atuação na cadeia produtiva e, por conseguinte, reduzindo sua capacidade como instrumento propulsor da política de conteúdo local do país e do desenvolvimento do município e da região (AZEVEDO e SILVA NETO, 2021).

Nesse contexto, este artigo tem como objetivo analisar os impactos da crise do contrachoque do petróleo de 2014 sobre o Arranjo Produtivo Local (APL) do petróleo e gás natural de Macaé, com destaque para o Quociente Locacional da aglomeração, sobre a arrecadação de royalties e participações especiais do município, sobre o número de estabelecimentos e de empregos formais, e sobre a remuneração e a escolaridade dos empregos das atividades relacionadas com a extração de petróleo.

A fim de atingir o objetivo proposto, de caráter exploratório e descritivo, adotou-se como procedimentos metodológicos o levantamento e a pesquisa bibliográfica sobre temas relativos à temática deste artigo. Os dados secundários foram levantados no Instituto Brasileiro de Geografia e Estatística (IBGE), sobretudo dados econômicos e populacionais, na plataforma de dados da RAIS (Relação Anual de Informações Sociais), relativos aos estabelecimentos, ao emprego formal e às suas características, e na Agência Nacional do Petróleo (ANP) e no Portal Inforoyalties, relativos às receitas de royalties e participações especiais. 
O artigo está estruturado, além desta Introdução, em outras cinco partes. Na primeira parte, aborda-se o contexto histórico da formação social e econômica de Macaé, com destaque para as transições dos seus diferentes ciclos econômicos. Em sequência, discute-se a temática do desenvolvimento econômico e das teorias com foco nas aglomerações produtivas e apresenta-se a configuração e a importância da aglomeração de petróleo e gás em Macaé. Na terceira parte, analisa-se os impactos da crise do contrachoque do petróleo de 2014 no arranjo produtivo do petróleo e gás nas receitas do município de Macaé, nos estabelecimentos, nos empregos formais e nas características do emprego das atividades relacionadas com a extração de petróleo. Ao final, apresentam-se as considerações finais e as referências do trabalho.

\section{UM OLHAR SOBRE O PASSADO RECENTE: UM MUNICÍPIO TRANSFORMADO PELO PETRÓLEO}

Macaé se caracteriza por um antes e depois à chegada da Petrobras. Até o final da década de 1970, o município era um pacato balneário, frequentado principalmente por campistas, que perdera há muito qualquer pretensa significância no conjunto de rede de cidades do interior fluminense. A cidade vivia às sombras da "maldição de Motta Coqueiro", que indignado por sua condenação à morte em um julgamento parcial, condenou Macaé a cem anos de atraso. Por coincidência, a chegada da Petrobras na cidade se deu cerca de 120 depois do enforcamento do fazendeiro ${ }^{4}$, reforçando essa lenda no folclore local.

Entretanto, Macaé não era um caso isolado no interior fluminense. Ao longo da maior parte do século XX, a estagnação econômica era a característica comum da maior parte dos municípios fluminenses ${ }^{5}$. Historicamente, a economia fluminense se polarizou em torno de três grandes estruturas regionais: (1) a economia urbana do Rio de Janeiro, impulsionada pela burocracia estatal, pelas atividades portuárias e pela indústria; (2) a cafeicultura nas atuais regiões do Médio Paraíba e Centro

\footnotetext{
${ }^{4}$ Manoel da Motta Coqueiro foi enforcado em 1855, acusado de ser o mandante do assassinato de uma família de 8 colonos de suas terras. Jurando inocência, rogou a clemência do imperador Pedro II, que a negou. Entretanto, depois ficou provado que tudo não passou de uma armação, pois não havia provas materiais de seu envolvimento no crime. Consternado, Pedro II passou a conceder clemência a todos os condenados à morte no Brasil, na prática extinguindo essa pena. A pena de morte, entretanto, só foi legalmente proibida no país após a Proclamação da República (http://www.macae.rj.gov.br/conteudo/leitura/titulo/a-historia-de-motta-coqueiro, acessado em 15 de julho de 2021).

${ }^{5}$ Cabe lembrar que até 15 de março de 1975, o estado do Rio de Janeiro era institucionalmente separado do atual município do Rio de Janeiro, que fora constituído em Município Neutro em 1834, Distrito Federal em 1891 e estado da Guanabara em 1960. Essa separação, derivada do fato do Rio de Janeiro ter sido capital do país, teve impactos profundos na formação socioeconômica fluminense, em destaque certa incapacidade de se pensar os problemas regionais a partir de uma perspectiva estadual.
} 
Sul Fluminense, que até a última década do século XIX colocou a então Província Fluminense na posição de mais rica região do Império e que, após a decadência da cafeicultura fluminense a partir de meados do século XX, passou a concentrar a maior parte da indústria de transformação do estado, excetuando a região metropolitana; e (3) a indústria sucroalcooleira no Norte Fluminense, em particular, no município de Campos dos Goytacazes, constituiu um polo relativamente autônomo em relação ao Rio de Janeiro, permitindo o desenvolvimento do núcleo urbano desse município como uma autêntica capital regional.

A descoberta em 1974 de petróleo na Bacia de Campos foi o ponto de virada da dinâmica regional fluminense e Macaé, por mera sorte locacional, tornou-se o epicentro dessa mudança ${ }^{6}$. Relativamente próxima do Rio de Janeiro e contando com o único porto disponível à época, ainda que pequeno, o município começou a receber as instalações de apoio à produção de petróleo da Petrobras a partir do final da década de 1970. A partir de então, o município passou por transformações disruptivas, das quais o intenso processo de urbanização e a consequente modernização da vida social urbana foram as mais intensas.

Conforme demonstrado na Tabela 1 a seguir, verifica-se que, a partir da década de 1980, o município apresentou um salto populacional, tornando-se um dos principais polos de atração imigratória do interior, de modo que, entre 2000 e 2010, foi o quarto município com maior crescimento demográfico absoluto ${ }^{7}$.

\begin{tabular}{|c|c|c|c|c|c|c|c|c|}
\hline \multicolumn{9}{|c|}{ Tabela 1: Evolução Populacional do Município de Macaé } \\
\hline & 1940 & 1950 & 1960 & 1970 & 1980 & 1991 & 2000 & 2010 \\
\hline Município (oficial censos) & 56.035 & 54.873 & 58.666 & 65.318 & 75.863 & 93.657 & 132.461 & 206.728 \\
\hline $\begin{array}{l}\text { Município (recorte após } \\
\text { 1989) }\end{array}$ & 28.961 & 27.839 & 41.972 & 47.221 & 59.403 & 93.657 & 132.461 & 206.728 \\
\hline $\begin{array}{l}\text { Posição por total de } \\
\text { população }\end{array}$ & $18^{\circ} / 92$ & $24^{\circ} / 92$ & $20^{\circ} / 92$ & $23^{\circ} / 92$ & $18^{\circ} / 64$ & $19^{\circ} / 92$ & $18^{\circ} / 92$ & $13^{\circ} / 92$ \\
\hline $\begin{array}{l}\text { Posição no crescimento } \\
\text { populacional }\end{array}$ & - & $79^{\circ} / 92$ & $18^{\circ} / 92$ & $34^{\circ} / 92$ & $18^{\circ} / 64$ & $12^{\circ} / 92$ & $9^{\circ} / 92$ & $4^{\circ} / 92$ \\
\hline
\end{tabular}

Fonte: Elaborado a partir dos dados dos censos demográficos do IBGE

\footnotetext{
${ }^{6}$ Crespo (2003) realizou interessante resgate das controvérsias dessa escolha nos jornais campistas no período.

${ }^{7}$ Macaé teve um acréscimo durante esse ínterim de 74.267 pessoas, atrás apenas do Rio de Janeiro (462.542), São Gonçalo (108.609) e Duque de Caxias (79.592). Cabe destacar que Rio das Ostras foi o quinto município de maior crescimento absoluto (69.257 pessoas). Ambos os municípios são hoje considerados partes de um mesmo arranjo populacional, juntamente com Conceição de Macabu, Casimiro de Abreu e Carapebus. Com efeito, o crescimento combinado de Macaé e Rio das Ostras entre 2000 e 2010 foi de 143.524 habitantes, enquanto no arranjo populacional como um todo cresceu 163.841 habitantes. Atrás apenas da região metropolitana, o arranjo populacional Macaé-Rio das Ostras foi, de longe, a região de maior atratividade absoluta (e relativa) de população do estado.
} 
Considerando as tendências anteriores à sorte de se encontrar reservas comercialmente exploráveis próximas à sua costa, os impactos sobre a microrregião foram avassaladores. Macaé e região se tornaram um laboratório para se investigar como se dava a transformação de um território relativamente estagnado a partir do súbito implante de um setor de alto conteúdo tecnológico.

Um dos temas mais instigantes era a tensão que se desenvolvia entre o tradicionalismo local e a modernização que se impunha na vida urbana (MONIÉ, 2003). Em poucos anos, o bucólico balneário tornou-se uma 'cidade de técnicos e engenheiros'.

Mal contando com uma única faculdade que formava profissionais para a educação básica, evidentemente que essa mão de obra especializada seria por um bom tempo formada fora do município. Para além da imigração desses profissionais, o Arranjo Produtivo Local (APL) de petróleo e gás passou a demandar a formação de quadros nos municípios da região com alguma estrutura educacional mais sofisticada. Isso abriu caminho para uma forte articulação de serviços educacionais tanto com a região metropolitana quanto com Campos dos Goytacazes. Essa população, com maior nível educacional, passou a demandar também maior quantidade (e qualidade) de serviços urbanos, tanto de natureza pública, quanto privada.

Levou tempo para que a institucionalidade local conseguisse se adequar ao que a nova realidade lhe impunha com velocidade ${ }^{8}$. A formação de novas culturas administrativas, intelectuais e institucionais se caracteriza por trajetórias acidentadas e que, não raro, dependem de mudanças geracionais para começarem a se consolidar. A própria relação entre a prefeitura local e a Petrobras precisou de tempo para alcançar algum nível de amadurecimento. De início, a relação entre a empresa estatal que atuava na fronteira tecnológica do setor e a estrutura política e burocrática absolutamente provinciana não teria outra solução senão a absoluta hierarquização. A despeito dessa condição hierárquica não ter se dissipado, pode-se dizer que tenha havido certa acomodação e naturalização da presença das cada vez mais numerosas empresas na cidade. Com o tempo, para o bem e para o mal, os instrumentos locais se modernizaram ${ }^{9}$ e foram se tornando mais coerentes com o novo perfil econômico local. O mesmo se pode dizer a respeito da vida social urbana. A alta massa salarial circulando pela cidade criou novas demandas de consumo, assim como oportunidades para maior sofisticação dos pequenos negócios. Recentemente, a partir das políticas federais de expansão da educação superior e profissional, Macaé começou a se constituir num polo universitário, com especial ênfase na formação

\footnotetext{
${ }^{8}$ O que não constitui nenhum absurdo, pois conforme Veblen (1965) apontava, as instituições evoluem, mas com inúmeras inércias.

${ }^{9}$ Para os quais, o aumento exponencial das rendas petrolíferas a partir de 1999 tiveram papel fundamental.
} 
de engenheiros, cientistas ambientais e profissionais da saúde.

Já faz mais de 40 anos desde que esse processo se iniciou e o bucólico balneário da década de 1970 tornou-se uma cidade média, de alta renda e relativamente sofisticada em termos de oferta de serviços urbanos. Isso vem sendo retratado pelos trabalhos de mapeamento da rede urbana brasileira realizados pelo IBGE, em que Macaé vem galgando funcionalidades e sendo um vetor central do aumento da complexidade urbana da região. Em 1987 e 1993, o IBGE classificava o município de Macaé como um centro sub-regional, porém com um nível de centralidade de médio para fraco, ou seja, não configurando na época um centro sub-regional consolidado. No estudo de 2007, o IBGE classificou Macaé como um centro sub-regional consolidado de nível A, logo abaixo da classificação de capital regional de nível B (classificação de Campos dos Goytacazes). No último estudo, publicado em 2018, o IBGE classificou Macaé como uma capital regional nível $\mathrm{C}$, dividindo o nível hierárquico com Campos do Goytacazes e Cabo Frio ${ }^{10}$. Cabe ainda destacar que, no estudo, identificou-se um arranjo populacional de nível médio na microrregião que engloba Macaé, Rio das Ostras, Casimiro de Abreu, Carapebus e Conceição de Macabu, fato fundamental para compreender a dinâmica regional impulsionada pelo desenvolvimento do APL de petróleo e gás no município.

Numa análise realizada na primeira metade dos anos 2000, o economista francês Yves Fauré sintetizou com precisão a rápida evolução do município no interior fluminense:

Alguns exemplos serão suficientes para confirmar essa mudança de identidade e funcional da cidade. (...) observou-se a instalação de representações com vocações regionais de serviços federais e estaduais (polícias civil e militar), a criação de sedes dos tribunais regionais e federais, sinal da elevação da cidade na hierarquia jurisdicional, a criação de escritórios regionais de organismos profissionais - tal como a poderosa FIRJAN e de suas numerosas ramificações administrativas - a chegada de instituições técnicas como o Inmetro que instalou, no local, um dos seus três estabelecimentos com responsabilidades sobre o conjunto do território nacional. A cidade tornou-se sede ou localização para representações e agências de associações profissionais $(\mathrm{OAB}$, Sindipetro etc. A maior parte dos serviços e estabelecimentos públicos renovaram ou ampliaram suas instalações - INSS, CEF etc. - os estabelecimentos bancários (BB, estabelecimentos financeiros privados), as empresas de transporte apresentaram as mesmas expansões. (FAURÉ, 2005, p. 229).

\footnotetext{
${ }^{10} \mathrm{O}$ IBGE, a despeito de utilizar a mesma matriz teórica em todos os seus estudos, no caso, a teoria das localidades centrais de Walterrf2 Christaller, vem atualizando a cada estudo sua classificação, de modo a dar conta das novas realidades urbanas que vêm se impondo no Brasil. Não obstante, verifica-se que não só Macaé, mas a região costeira norte do estado do Rio de Janeiro vem se tornando uma área cada vez mais urbanizada e integrada, o que tem levantado a hipótese de que já faz parte da megarregião São Paulo-Rio de Janeiro identificada por Sandra Lencioni (2015).
} 
Como apresentado, o incremento de funções urbanas só fez crescer desde então, dos quais destaca-se o implante de importante polo universitário público a partir da política de expansão das universidades federais no final daquela década, mas também de instituições de ensino superior privadas que se instalaram na cidade.

Acompanhou também essa rápida expansão, o recrudescimento dos problemas urbanos já conhecidos nas grandes cidades brasileiras. A despeito do dinamismo do mercado de trabalho formal do município, que cresceu de forma contínua até 2014, e cujo estoque chegava a mais de $70 \%$ da população economicamente ativa do município em 2010, uma parte significativa da população macaense não se inseriu ou foi inserida precariamente nesse processo. A favelização é uma das partes mais importantes da urbanização macaense, que se fez acompanhar de aumentos críticos da violência urbana, em especial, após as políticas de ocupação policial das favelas cariocas em razão dos grandes eventos esportivos que ali se realizariam ${ }^{11}$. A par desses graves problemas sociais, somam-se a piora dos índices de poluição ambiental e a saturação e a obsolescência da infraestrutura urbana, cujas soluções acontecem de forma bastante retardatária no tempo.

\section{O APL DE PETRÓLEO E GÁS NATURAL DE MACAÉ: ESPECIALIZAÇÃO E DINÂMICA DAS PRINCIPAIS ATIVIDADES ECONÔMICAS}

Já é reconhecido que a partir da instalação da estrutura de apoio à produção de petróleo e gás natural em Macaé, se formou ao longo do tempo um arranjo produtivo local altamente especializado.

No Brasil, o conceito de Arranjos Produtivos Locais (APL) foi criado e desenvolvido pela RedeSist em finais da década de 1990 tendo rapidamente se disseminado na esfera de ensino e pesquisa e de política (BRITO e VARGAS, 2015). Segundo os referidos autores, de acordo com a definição proposta pela RedeSist, Arranjos e Sistemas Produtivos e Inovativos representa fundamentalmente um quadro de referências, a partir do qual se busca compreender os processos de geração, difusão e uso de conhecimentos e da dinâmica produtiva e inovativa. Tal abordagem oferece um novo instrumental para entender e orientar o desenvolvimento industrial e tecnológico.

\footnotetext{
${ }^{11}$ Fenômeno que ocorreu em grande parte das cidades médias fluminenses, em especial no circuito litorâneo norte e sul do estado. Em particular com a instalação das UPPs, a expansão do modelo carioca de territorialização das favelas pelos grupos criminosos se replicou nessas cidades, que passaram a conviver com tiroteios entre facções e entre policiais (BOPE e CORE inclusos) e essas facções. Mais recentemente, expandem-se também por essas cidades médias, Macaé incluso, os tentáculos das milícias.
} 
O desenvolvimento do conceito tem permitido descrever e investigar os aglomerados produtivos existentes nos espaços periféricos. Trata-se, na verdade, de uma tradução para a realidade brasileira da retomada dos distritos industriais marshalianos, que passaram a ser uma constante nos estudos de economia regional e geografia econômica a partir da década de 1980. Nesse sentido, os APLs foram definidos:

... como "aglomerados de agentes econômicos, políticos e sociais, localizados num mesmo território, que apresentam vínculos consistentes de articulação, interação, cooperação e aprendizagem, incluindo não apenas firmas (produtoras de bens e serviços finais, insumos e equipamentos, prestadoras de serviços, comerciantes, clientes etc. e suas diversas formas de representação e associação), mas também outras instituições públicas e privadas voltadas à formação e treinamento de recursos humanos, pesquisa, desenvolvimento e engenharia, promoção e financiamento" (LASTRES E CASSIOLATO, 2003; ROSENDO, 2004).

Lastres e Cassiolato (2003), ao desenvolverem o conceito de Arranjo Produtivo Local aplicado à análise de aglomerações em regiões de baixo e médio desenvolvimento, apresentam a seguinte definição:

Arranjos produtivos locais - São aglomerações territoriais de agentes econômicos, políticos e sociais - com foco em um conjunto específico - que apresentam vínculos mesmo que incipientes. Geralmente envolvem a participação e a interação de empresas que podem ser desde produtoras de bens e serviços finais até fornecedoras de insumos e equipamentos, prestadoras de consultoria e serviços, comercializadoras, clientes e outros - e suas variadas formas de representação e associação. Incluem também diversas outras instituições públicas e privadas voltadas para: formação e capacitação de recursos humanos (como escolas técnicas e universidades); pesquisa, desenvolvimento, engenharia; política, promoção e financiamento (LASTRES E CASSIOLATO, 2003, p.11).

Integrante à teoria evolucionária, a abordagem de Arranjo Produtivo Local considera que as aglomerações de empresas em um dado espaço e suas dinâmicas produtivas são resultado das intenções que estabelecem entre si e com outras instituições, como governos, sindicatos, bancos etc. A abordagem de APL, embora se valha de conceitos teóricos evolucionários, em especial aqueles ligados à teoria de sistemas de inovação, tem como foco o estudo de aglomerações produtivas em regiões de baixo e médio desenvolvimento (Lastres e Cassiolato, 2003, p.12).

Considerando que a concentração especializada de um setor ou um conjunto de setores produtivos num dado território é a condição sine qua non para a existência de um arranjo produtivo local, a primeira tarefa para sua identificação é mensurar se há ou não especialização produtiva e qual seu grau de importância. O método mais usual para a identificação das especializações produtivas no território é o Quociente Locacional (QL). O QL é encontrado a partir do seguinte cálculo 
(1) $Q L=\left(E_{i j} / E_{j}\right) /\left(E_{i B r} / E_{B r}\right)$

Onde:

(2) $E_{i j}=$ estoque de emprego da atividade ' $i$ ' no território ' $j$ '

(3) $E_{j}=$ estoque total de emprego no território ' $j$ '

(4) $E_{i B r}=$ estoque de emprego da atividade ' $i$ ' no Brasil

(5) $E_{B r}=$ estoque total de emprego no Brasil

Se o resultado for igual a 1, significa que o território 'j' possui uma concentração da atividade 'i' igual à média brasileira. Se o resultado for inferior a 1, a concentração é menor que a média brasileira, assim como se for superior a 1, pode-se definir que há alguma especialização da atividade no território ‘j'. É evidente que o QL apenas faz o primeiro diagnóstico do grau de especialização. Outros indicadores precisam ser refinados, dentre os quais a participação relativa da eventual concentração produtiva frente ao conjunto dos empregos da atividade no país.

Segundo Hasenclever et al (2015), as atividades de exploração e produção de petróleo e gás natural offshore possuem efeitos multiplicadores de empregos indiretos relativamente modestos, quando comparados com outros setores da indústria. Isso se deve ao fato de as demandas específicas do setor exigirem investimentos intensivos em capital. Essa informação é confirmada quando se verifica a participação dos empregos da extração mineral no total do estoque de empregos é muito baixa, tanto no Brasil (0,5\% do total dos empregos em 2014), quanto no próprio estado do Rio de Janeiro (ERJ), que é um dos estados mais especializados na extração mineral (apesar de concentrar quase 20\% dos empregos no subsetor, este representava apenas 1,1\% do total do estoque estadual em 2014). Não obstante, as atividades de exploração e produção, por razões óbvias, são altamente concentradas no território, principalmente no que se refere à exploração offshore, o que se traduz em profundos impactos nas regiões onde os capitais fixos da cadeia produtiva se instalam.

Esse foi, o caso do arranjo produtivo de petróleo e gás natural em Macaé, que se configurou quase num modelo "perrouxiano" de enclave territorial a partir de um setor motriz ${ }^{12}$. Segundo Silva e Britto (2009) o arranjo produtivo de petróleo e gás natural de Macaé é do tipo centrorradial, sendo a Petrobras a empresa âncora que impulsiona, por meio de seus contratos, fornecedores de primeiro

\footnotetext{
${ }^{12}$ François Perroux formulou em 1950 a hipótese dos polos de crescimento como o móvel para o desenvolvimento desequilibrado do capitalismo. O polo de crescimento seria resultado de uma indústria motriz, geralmente conduzida por uma ou algumas grandes empresas, que irradiaria seus efeitos econômicos para outros setores. Tal proposição foi complementada pelo economista estadunidense Alfred Hirschman, ao identificar os efeitos de encadeamento para frente e para trás a partir desses setores motrizes. Esses dois autores foram os mais importantes para as políticas de desenvolvimento regional implantadas no mundo todo até a década de 1970. No Brasil, as superintendências regionais (Sudene, Sudam e outras) tentaram implantar o modelo no país. O II Plano Nacional de Desenvolvimento também teve na noção do crescimento polarizado um dos seus referenciais, de modo que foi o argumento central para a imposição da fusão entre os então estados da Guanabara e do Rio de Janeiro em 1974.
} 
nível, formadas pelas para-petroleiras internacionais e grandes empresas de engenharia nacionais, e as fornecedoras de segundo nível, formadas principalmente por pequenas e médias empresas locais, em sua maioria operando em regime de subcontratação ${ }^{13}$. O arranjo é formado por uma complexa teia de atividades de alta especialização tanto nas fases de exploração (sísmica 3D, perfuração de poços, transporte e aluguel de plataformas etc), quanto na fase de desenvolvimento da produção (colocação de árvores de natal, instalação de dutos de óleo e gás, minifolds, bombas elétricas, instalação de plataformas fixas e flutuantes, reparos navais, etc), que são executadas por empresas industriais e prestadoras de serviços. Além dessas atividades do núcleo da exploração e produção, o arranjo fomentou ainda um extenso tecido de atividades de comércio de produtos industriais, assim como serviços de menor exigência tecnológica, como hotelaria e catering.

Já em 1985, quando se inicia a série histórica da Relação Anual de Informações Sociais (RAIS) do Ministério do Trabalho, poucos anos após a primeira produção comercial na Bacia de Campos, Macaé já apresentava elevado quociente locacional no subsetor de extração mineral, ultrapassando o índice 40 de concentração.

Com a publicação da Classificação Nacional das Atividades Econômicas (CNAE) em 1994 pelo IBGE, foi possível constatar com mais precisão o processo de estruturação do arranjo produtivo de petróleo e gás natural no município. Neste trabalho, optou-se por iniciar a análise da série histórica em 2002, em virtude da maior confiabilidade das informações ${ }^{14}$. Nesse ano, 2002, observa-se os elevados níveis de especialização de Macaé em várias atividades.

Na Tabela 2, abaixo, foram listadas, para os anos 2002, 2014 (ano da crise do contrachoque do petróleo) e 2019, as 10 atividades mais especializadas de Macaé. Em 2002, destacam-se as atividades de 'extração de petróleo e gás natural' e os 'serviços de apoio à extração de petróleo e gás natural', que representavam, respectivamente, Participação Relativa (PR) de 52,2\% e 49,9\% do estoque do país.

\footnotetext{
${ }^{13}$ O estudo de Silva e Britto (2009) apresenta ainda interessante análise sobre como a mudança do modelo de contratação da Petrobras impacta a estruturação do arranjo, determinando as barreiras de entrada e o nível de eficiência da rede de contratadas. Na pesquisa realizada pelos autores, demonstra-se que as mudanças realizadas pela estatal desde 2002 vinha tornando mais concentrado o mercado, reduzindo a participação de pequenas e médias empresas como contratadas diretas da empresa. Em razão desse processo, criaram-se algumas inciativas de apoio e fortalecimento das empresas fornecedoras de menor porte, dentre as quais se destaca a Redepetro - BC, analisada por Dias (2013). Uma atualização dessas análises faz-se necessária, pois após 2015 a Petrobras vem sofrendo profunda reestruturação, inclusive com venda de ativos, fruto de uma agenda liberal que levará a novas configurações a indústria de petróleo no país.

${ }^{14}$ Ao longo da coleta de dados, verificou-se uma flutuação pouco provável entre 1995, 1996 e 1997 nas atividades de exploração de petróleo e gás natural e nos serviços de apoio à extração de petróleo e gás natural. Não sendo possível verificar as razões dessa flutuação, supomos que houve inconsistências na coleta dos dados pelo então Ministério do Trabalho e Emprego. Optamos, portanto, por iniciar a análise em 2002, quando o sistema de coleta já estava mais consolidado e os dados mais confiáveis.
} 
Essas são as duas atividades motrizes do mercado de trabalho local, impulsionando inclusive a especialização de outras atividades no município (e na região de entorno imediata, em particular Rio das Ostras). Conforme é possível verificar na Tabela 2, existiu certa variação na lista das 10 atividades mais especializadas em Macaé, porém a liderança da 'extração de petróleo e gás' e dos 'serviços de apoio' é incontestável ao longo da série histórica da CNAE 95 analisada.

\begin{tabular}{|c|c|c|c|c|c|c|c|}
\hline \multicolumn{8}{|c|}{$\begin{array}{c}\text { Tabela 2: Quociente locacional em Macaé - Anos selecionados } \\
\text { Grupos de atividades CNAE } 95 \text { - ano } 2002\end{array}$} \\
\hline & $\begin{array}{l}\text { Estoque } \\
\text { de } \\
\text { Empregos } \\
2002 \\
\end{array}$ & $\begin{array}{l}\text { No de } \\
\text { Estabele } \\
\text { cimentos }\end{array}$ & $\begin{array}{c}\text { Porte } \\
\text { médio } \\
\text { dos } \\
\text { Estabele } \\
\text { cimentos }\end{array}$ & QL & $\begin{array}{c}\text { PR } \\
\text { estoque } \\
\text { munici- } \\
\text { pal }\end{array}$ & $\begin{array}{l}\text { PR } \\
\text { Ativi } \\
\text { dade } \\
\text { BR }\end{array}$ & $\begin{array}{c}\text { PR } \\
\text { Ativida } \\
\text { de ERJ }\end{array}$ \\
\hline $\begin{array}{l}\text { Extração de petróleo e } \\
\text { gás Natural }\end{array}$ & 7.819 & 15 & 521 & 264,662 & $13,8 \%$ & $52,2 \%$ & $93,1 \%$ \\
\hline $\begin{array}{l}\text { Atividades de serviços } \\
\text { relacionados com a } \\
\text { extração de petróleo e } \\
\text { gás exceto a prospecção } \\
\text { realizada por terceiros }\end{array}$ & 3.582 & 27 & 133 & 253,215 & $6,3 \%$ & $49,9 \%$ & $76,9 \%$ \\
\hline $\begin{array}{l}\text { Transporte marítimo de } \\
\text { cabotagem e longo curso }\end{array}$ & 1.285 & 9 & 143 & 71,053 & $2,3 \%$ & $14,0 \%$ & $18,8 \%$ \\
\hline $\begin{array}{l}\text { Transporte aéreo, não } \\
\text { regular }\end{array}$ & 306 & 4 & 77 & 33,715 & $0,5 \%$ & $6,6 \%$ & $28,0 \%$ \\
\hline $\begin{array}{l}\text { Fabricação de máquinas } \\
\text { e equipamentos de uso } \\
\text { na extração mineral e } \\
\text { construção }\end{array}$ & 700 & 10 & 70 & 31,912 & $1,2 \%$ & $6,3 \%$ & $39,7 \%$ \\
\hline Preparação do terreno & 1.332 & 5 & 266 & 19,256 & $2,4 \%$ & $3,8 \%$ & $30,9 \%$ \\
\hline $\begin{array}{l}\text { Construção e reparação } \\
\text { de embarcações }\end{array}$ & 336 & 4 & 84 & 14,256 & $0,6 \%$ & $2,8 \%$ & $4,1 \%$ \\
\hline $\begin{array}{l}\text { Outros transportes } \\
\text { aquaviários }\end{array}$ & 257 & 4 & 64 & 13,970 & $0,5 \%$ & $2,8 \%$ & $17,4 \%$ \\
\hline Transporte dutoviário & 153 & 1 & 153 & 12,605 & $0,3 \%$ & $2,5 \%$ & $27,9 \%$ \\
\hline Obras de Instalações & 1.917 & 12 & 160 & 10,465 & $3,4 \%$ & $2,1 \%$ & $13,0 \%$ \\
\hline
\end{tabular}


Grupos de atividades CNAE 95 - ano 2014

\begin{tabular}{|c|c|c|c|c|c|c|c|}
\hline & \begin{tabular}{|l} 
Estoque \\
de \\
Empregos \\
2014 \\
\end{tabular} & $\begin{array}{l}\text { No de } \\
\text { Estabele } \\
\text { cimentos }\end{array}$ & $\begin{array}{c}\text { Porte } \\
\text { médio } \\
\text { dos } \\
\text { Estabele } \\
\text { cimentos }\end{array}$ & QL & $\begin{array}{c}\text { PR } \\
\text { estoque } \\
\text { munici- } \\
\text { pal }\end{array}$ & $\begin{array}{c}\text { PR } \\
\text { Ativi } \\
\text { dade } \\
\text { BR }\end{array}$ & $\begin{array}{c}\text { PR } \\
\text { Ativida } \\
\text { de ERJ }\end{array}$ \\
\hline $\begin{array}{l}\text { Atividades de serviços } \\
\text { relacionados com a } \\
\text { extração de petróleo e gás } \\
\text { exceto a prospecção } \\
\text { realizada por terceiros }\end{array}$ & 14.856 & 68 & 218 & 165,955 & $10,0 \%$ & $49,5 \%$ & $66,3 \%$ \\
\hline $\begin{array}{l}\text { Extração de petróleo e gás } \\
\text { natural }\end{array}$ & 13.902 & 7 & 1.986 & 146,539 & $9,4 \%$ & $43,7 \%$ & $74,6 \%$ \\
\hline Transporte dutoviário & 444 & 1 & 444 & 43,379 & $0,3 \%$ & $12,9 \%$ & $40,4 \%$ \\
\hline $\begin{array}{l}\text { Transporte marítimo de } \\
\text { cabotagem e longo curso }\end{array}$ & 846 & 8 & 106 & 30,213 & $0,6 \%$ & $9,0 \%$ & $10,9 \%$ \\
\hline $\begin{array}{l}\text { Transporte aéreo, não } \\
\text { regular }\end{array}$ & 642 & 6 & 107 & 27,591 & $0,4 \%$ & $8,2 \%$ & $18,6 \%$ \\
\hline $\begin{array}{l}\text { Fabricação de máquinas e } \\
\text { equipamentos de uso na } \\
\text { extração mineral e } \\
\text { construção }\end{array}$ & 1.635 & 7 & 234 & 19,717 & $1,1 \%$ & $5,9 \%$ & $32,7 \%$ \\
\hline $\begin{array}{l}\text { Manutenção e reparação de } \\
\text { máquinas e equipamentos } \\
\text { industriais }\end{array}$ & 4.077 & 47 & 87 & 16,293 & $2,8 \%$ & $4,9 \%$ & $33,9 \%$ \\
\hline $\begin{array}{l}\text { Ensaios de materiais e de } \\
\text { produtos }\end{array}$ & 905 & 18 & 50 & 12,409 & $0,6 \%$ & $3,7 \%$ & $14,7 \%$ \\
\hline $\begin{array}{l}\text { Atividades relacionadas à } \\
\text { organização do transporte } \\
\text { de cargas }\end{array}$ & 2.502 & 17 & 147 & 9,65 & $1,7 \%$ & $2,9 \%$ & $22,8 \%$ \\
\hline $\begin{array}{l}\text { Atividades auxiliares dos } \\
\text { transportes }\end{array}$ & 6.537 & 56 & 117 & 9,519 & $4,4 \%$ & $2,8 \%$ & $15,5 \%$ \\
\hline \multicolumn{8}{|c|}{ Grupos de atividades CNAE 95 - ano 2019} \\
\hline & $\begin{array}{c}\text { Estoque } \\
\text { de } \\
\text { Empregos } \\
2019\end{array}$ & $\begin{array}{l}\text { No de } \\
\text { Estabele } \\
\text { cimentos }\end{array}$ & $\begin{array}{c}\text { Porte } \\
\text { médio } \\
\text { dos } \\
\text { Estabele } \\
\text { cimentos }\end{array}$ & QL & $\begin{array}{c}\text { PR } \\
\text { estoque } \\
\text { munici- } \\
\text { pal }\end{array}$ & $\begin{array}{c}\text { PR } \\
\text { Ativi } \\
\text { dade } \\
\text { BR }\end{array}$ & $\begin{array}{c}\text { PR } \\
\text { Ativida } \\
\text { de ERJ }\end{array}$ \\
\hline $\begin{array}{l}\text { Atividades de serviços } \\
\text { relacionados com a } \\
\text { extração de petróleo e } \\
\text { gás exceto a prospecção } \\
\text { realizada por terceiros }\end{array}$ & 10.970 & 58 & 189 & 176,967 & $9,0 \%$ & $45,5 \%$ & $63,0 \%$ \\
\hline $\begin{array}{l}\text { Extração de petróleo e } \\
\text { gás natural }\end{array}$ & 9.776 & 7 & 1.397 & 147,704 & $8,0 \%$ & $38,0 \%$ & $68,8 \%$ \\
\hline $\begin{array}{l}\text { Construção e reparação } \\
\text { de embarcações }\end{array}$ & 2.769 & 11 & 252 & 41,818 & $2,3 \%$ & $10,8 \%$ & $21,7 \%$ \\
\hline $\begin{array}{l}\text { Transporte marítimo de } \\
\text { cabotagem e longo curso }\end{array}$ & 428 & 4 & 107 & 37,737 & $0,3 \%$ & $9,7 \%$ & $15,8 \%$ \\
\hline $\begin{array}{l}\text { Manutenção e reparação } \\
\text { de máquinas e } \\
\text { equipamentos industriais }\end{array}$ & 6.045 & 55 & 110 & 26,001 & $4,9 \%$ & $6,7 \%$ & $44,7 \%$ \\
\hline $\begin{array}{l}\text { Aluguel de outros meios } \\
\text { de transporte }\end{array}$ & 484 & 7 & 69 & 22,851 & $0,4 \%$ & $5,9 \%$ & $28,6 \%$ \\
\hline Transporte dutoviário & 379 & 1 & 379 & 20,411 & $0,3 \%$ & $5,3 \%$ & $8,0 \%$ \\
\hline $\begin{array}{l}\text { Transporte aéreo, não } \\
\text { regular }\end{array}$ & 304 & 5 & 61 & 20,282 & $0,2 \%$ & $5,2 \%$ & $13,1 \%$ \\
\hline $\begin{array}{l}\text { Fabricação de máquinas } \\
\text { e equipamentos de uso } \\
\text { na extração mineral e } \\
\text { construção }\end{array}$ & 835 & 7 & 119 & 14,147 & $0,7 \%$ & $3,6 \%$ & $18,6 \%$ \\
\hline
\end{tabular}

Fonte: Elaborado pelos autores a partir dos dados da RAIS (2021) 
Ainda no que se refere aos dados apresentados na Tabela 2, observa-se que a participação desses setores especializados no estoque municipal é muito importante, e muito maior do que o representado no total do mercado de trabalho estadual e brasileiro. Em 2002, somente as dez atividades de maior QL somavam juntas $31 \%$ do mercado de trabalho formal de Macaé, sendo que só as atividades de extração de petróleo e gás natural e os serviços de apoio somavam juntas $20 \%$ do estoque municipal. O ano de 2014 foi o auge do boom de empregos formais em Macaé, que alcançou o patamar de mais de 147 mil empregos no município, de longe o mercado de maior tamanho e dinamismo do interior fluminense. Mas também foi o último ano antes do início dos principais impactos da crise do contrachoque do petróleo. Nesse ano, verificou-se um quadro semelhante ao de 2002, em que as atividades de alto QL representam $31 \%$ do mercado de trabalho formal do município, ainda que no rol das 10 atividades que mais empregam façam parte apenas os 'serviços de apoio à extração de petróleo e gás', as 'atividades de extração de petróleo e gás' e as 'atividades auxiliares dos transportes'. As atividades motrizes da cadeia produtiva de petróleo e gás natural empregaram 19,4\% do estoque, sendo a segunda e terceira atividade que mais empregavam no município, atrás, somente, das atividades ligadas à administração pública.

Considerando os salários mais altos pagos por essas duas atividades (ver DIAS, 2020), esse fato foi muito importante para impulsionar uma série de atividades terciárias em Macaé, que passaram a contratar grande contingente de mão de obra. Outro dado digno de nota foi o aumento geral do porte médio dos estabelecimentos, sendo que em vários das atividades há um número reduzido de empresas atuando.

A partir de 2015, conforme se observa no Gráfico 1, começa-se a se observar os impactos da crise do contrachoque no estoque de empregos formais de Macaé. As principais causas foram: os fatores como as forças de oferta e demanda, os fatores geopolíticos, a financeirização do petróleo, as mudanças no marco regulatório do petróleo no país, e a crise política no país que, por sua vez, dentre vários fatores, foi motivada também pela Operação Lava Jato. Tais fatores conjugados provocaram profundos impactos no setor, reduzindo sua capacidade como instrumento propulsor da política de conteúdo local do país e do desenvolvimento do município e da região (AZEVEDO e SILVA NETO, 2020). 
Gráfico 1: Evolução do Número de Empregos Formais em Macaé (2002 a 2019)

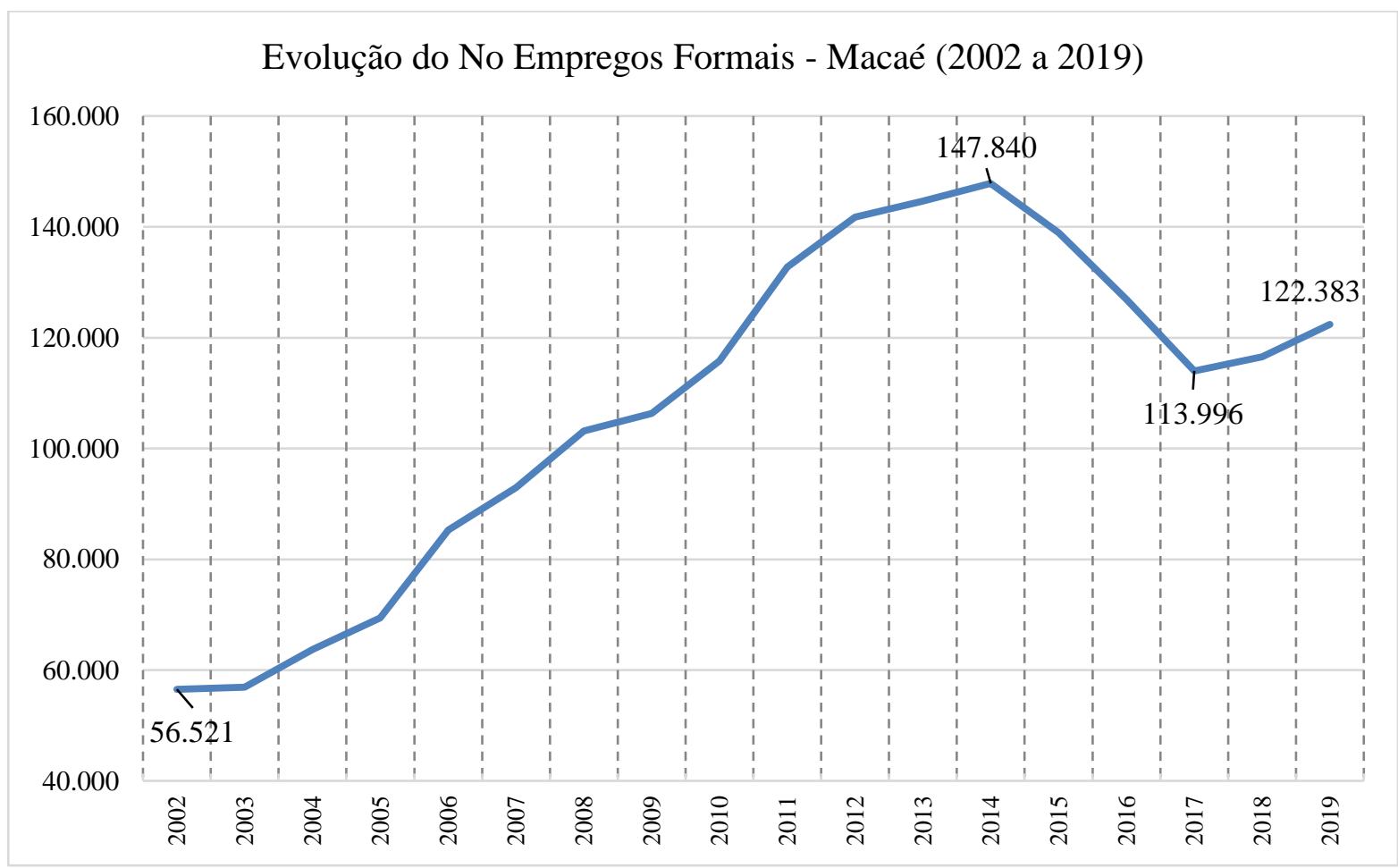

Fonte: RAIS (2021)

Em 2019, final da série histórica disponível na RAIS, observa-se na Tabela 2 e no Gráfico 1 um quadro diferente. O mercado de trabalho formal do município foi um dos mais afetados no ERJ, que também foi um dos estados que mais perderam empregos no período. Entre 2015 e 2017 Macaé passou por um continuado processo de perda de empregos (estoque de 113.996 empregos em 2017), que só começou a inverter o processo em 2018 e chegou no fim de 2019 com um estoque de 122.383 empregos formais. Naturalmente, isso refletiu no conjunto das 10 atividades de mais alto QL, que perdeu participação no estoque municipal, concentrado $26,1 \%$ do estoque municipal em 2019 , contra os $31 \%$ dos anos anteriores. Da mesma maneira, as atividades de 'exploração de petróleo e gás natural' e as 'atividades de apoio' retrocederam sua participação conjunta a $17 \%$ do estoque total, contra os $20 \%$ de 2002 e os $19,4 \%$ de 2014.

Ainda assim, quando consideradas as dez atividades de maior impacto local na geração de empregos ao longo do período analisado, apesar da crise e da perda relativa de empregos, verifica-se a importância continuada das atividades da cadeia produtiva de petróleo e gás natural, confirmando o caráter de enclave já apontado anteriormente, mesmo com a redução do QL. Como afirmado, nas 
escalas nacional e estadual, por mais importante que seja a indústria de petróleo e gás natural como um todo, a participação das atividades envolvidas na exploração e produção de petróleo e gás possuem uma participação bastante discreta no mercado de trabalho formal. Em Macaé, entretanto, são justamente essas atividades as principais do município, mesmo com o declínio observado nos dados analisados.

Outro destaque importante é que, com o crescimento da cidade e sua consequente sofisticação, como apontado na primeira parte deste trabalho, novas demandas sociais surgiram e que podem ser reveladas nos dados da Tabela 3 a seguir. Em primeiro lugar, cabe destacar a notável expansão das atividades do setor público, respondendo às demandas por serviços coletivos da população que crescia. Em 2002, Macaé possuía uma participação bastante modesta das atividades de administração do Estado e da política econômica e social, cerca de 6\% do estoque. Em 2014 e 2019, essa proporção subiu para $11 \%$ e 13\%, que, é importante dizer, é uma participação ainda abaixo da média brasileira e fluminense. Em segundo lugar, verifica-se a importância adquirida pelas atividades de restaurantes e serviços de alimentação e de atenção à saúde, respondendo tanto às novas necessidades de consumo, quanto, mais uma vez, às demandas de serviços de interesse coletivo. 


\begin{tabular}{|c|c|c|c|c|c|}
\hline \multicolumn{6}{|c|}{ Tabela 3: Maiores estoques - Anos selecionados } \\
\hline 2002 & & 2014 & & 2019 & \\
\hline $\begin{array}{l}\text { Extração de petróleo } \\
\text { e gás natural }\end{array}$ & 7.819 & $\begin{array}{l}\text { Administração do } \\
\text { estado e da política } \\
\text { econômica e social }\end{array}$ & 15.992 & $\begin{array}{l}\text { Administração do } \\
\text { estado e da política } \\
\text { econômica e social }\end{array}$ & 15.819 \\
\hline $\begin{array}{l}\text { Outras atividades de } \\
\text { serviços prestados } \\
\text { principalmente às } \\
\text { empresas }\end{array}$ & 4.863 & $\begin{array}{l}\text { Atividades de serviços } \\
\text { relacionados com a } \\
\text { extração de petróleo e } \\
\text { gás exceto a } \\
\text { prospecção realizada } \\
\text { por terceiros }\end{array}$ & 14.856 & $\begin{array}{l}\text { Atividades de serviços } \\
\text { relacionados com a } \\
\text { extração de petróleo e } \\
\text { gás exceto a } \\
\text { prospecção realizada } \\
\text { por terceiros }\end{array}$ & 10.970 \\
\hline $\begin{array}{l}\text { Construção de } \\
\text { edifícios e obras de } \\
\text { engenharia civil }\end{array}$ & 4.346 & $\begin{array}{l}\text { Construção de } \\
\text { edifícios e obras de } \\
\text { engenharia civil }\end{array}$ & 14.328 & $\begin{array}{l}\text { Extração de petróleo e } \\
\text { gás natural }\end{array}$ & 9.776 \\
\hline $\begin{array}{l}\text { Atividades de } \\
\text { serviços } \\
\text { relacionados com a } \\
\text { extração de petróleo } \\
\text { e gás, exceto a } \\
\text { prospecção realizada } \\
\text { por terceiros }\end{array}$ & 3.582 & $\begin{array}{l}\text { Extração de petróleo e } \\
\text { gás natural }\end{array}$ & 13.902 & $\begin{array}{l}\text { Construção de } \\
\text { edifícios e obras de } \\
\text { engenharia civil }\end{array}$ & 9.522 \\
\hline $\begin{array}{l}\text { Administração do } \\
\text { estado e da política } \\
\text { econômica e social }\end{array}$ & 3.554 & $\begin{array}{l}\text { Restaurantes e outros } \\
\text { estabelecimentos de } \\
\text { serviços de } \\
\text { alimentação }\end{array}$ & 9.754 & $\begin{array}{l}\text { Restaurantes e outros } \\
\text { estabelecimentos de } \\
\text { serviços de } \\
\text { alimentação }\end{array}$ & 7.043 \\
\hline $\begin{array}{l}\text { Restaurantes e } \\
\text { outros } \\
\text { estabelecimentos de } \\
\text { serviços de } \\
\text { alimentação }\end{array}$ & 3.379 & $\begin{array}{l}\text { Outras atividades de } \\
\text { serviços prestados } \\
\text { principalmente às } \\
\text { empresas }\end{array}$ & 6.734 & $\begin{array}{l}\text { Atividades auxiliares } \\
\text { dos transportes }\end{array}$ & 6.261 \\
\hline $\begin{array}{l}\text { Comércio varejista } \\
\text { de outros produtos }\end{array}$ & 2.898 & $\begin{array}{l}\text { Atividades auxiliares } \\
\text { dos transportes }\end{array}$ & 6.537 & $\begin{array}{l}\text { Outros transportes } \\
\text { terrestres }\end{array}$ & 6.092 \\
\hline Obras de instalações & 1.917 & $\begin{array}{l}\text { Outros transportes } \\
\text { terrestres }\end{array}$ & 6.358 & $\begin{array}{l}\text { Manutenção e } \\
\text { reparação de máquinas } \\
\text { e equipamentos } \\
\text { industriais }\end{array}$ & 6.045 \\
\hline $\begin{array}{l}\text { Outros transportes } \\
\text { terrestres }\end{array}$ & 1.639 & $\begin{array}{l}\text { Comércio varejista de } \\
\text { outros produtos }\end{array}$ & 5.885 & $\begin{array}{l}\text { Comércio varejista de } \\
\text { outros produtos }\end{array}$ & 4.125 \\
\hline $\begin{array}{l}\text { Serviços de } \\
\text { arquitetura e } \\
\text { engenharia e de } \\
\text { assessoramento } \\
\text { técnico } \\
\text { especializado }\end{array}$ & 1.499 & $\begin{array}{l}\text { Atividades de atenção } \\
\text { à saúde }\end{array}$ & 4.609 & $\begin{array}{l}\text { Serviços de arquitetura } \\
\text { e engenharia e de } \\
\text { assessoramento } \\
\text { técnico especializado }\end{array}$ & 4.045 \\
\hline
\end{tabular}

Fonte: Elaborado pelos autores a partir dos dados da RAIS (2021) 


\section{AS INCERTEZAS DO FUTURO: DESCONCENTRAÇÃO GEOGRÁFICA E REESTRUTURAÇÃO DAS EMPRESAS E DO MERCADO DE TRABALHO DO ARRANJO PRODUTIVO DE PETRÓLEO E GÁS NATURAL}

\subsection{Desconcentração geográfica do arranjo produtivo de petróleo e gás}

O desenvolvimento das atividades na Bacia de Campos transformou completamente a dinâmica regional da costa norte do estado do Rio de Janeiro, em especial a partir do final da década de 1990, com a conjunção do amadurecimento dos investimentos realizados pela Petrobras e das mudanças regulatórias oriundas da Lei do Petróleo de 1997. Com efeito, configurou-se, segundo Pessanha (2015), dois tipos de impacto econômico na região: (1) a 'economia do petróleo', derivada da instalação da cadeia produtiva no território, deu-se de forma concentrada em Macaé e, mais recentemente, em Rio das Ostras e São João da Barra (a partir da construção do Porto do Açu); e (2) a 'economia dos royalties', derivada do inchaço dos orçamentos municipais a partir dos repasses das participações governamentais, foi o efeito econômico mais espraiado, contemplando principalmente os municípios confrontantes com as jazidas de petróleo em alto-mar.

Beneficiado duplamente pela economia do petróleo e pela economia dos royalties, o município de Macaé, como visto, usufruiu de mais de três décadas de ininterrupto crescimento do arranjo produtivo de petróleo e gás, com todos os impactos positivos e negativos sintetizados na primeira parte deste trabalho. Entretanto, a partir do final da década de 2000, dois eventos começaram a modificar as perspectivas do setor de petróleo e gás natural no Brasil. O primeiro deles, foi a descoberta das gigantescas reservas de petróleo e gás natural no pré-sal da Bacia de Santos, que além da quantidade, apresentou a presença de óleo de melhor qualidade do que aquele produzido no pós sal da Bacia de Campos. Isso por si só redefiniria as centralidades de todo o setor, de modo a reposicionar o arranjo produtivo em Macaé no conjunto da nova dinâmica territorial que emergiria da exploração dessa nova província.

A segunda grande mudança foram os efeitos do contrachoque do petróleo de 2014, que atuou na redução drástica das receitas do petrorrentismo, por um lado, e no profundo impacto negativo da Operação Lava Jato, que abriu caminho para um "cavalo de pau" na indústria petrolífera, com a reestruturação da Petrobras no sentido de reduzir sua participação no negócio do petróleo. Conformeanalisado em Dias (2020), essa crise que, como se sabe, foi também política, teve um impacto imenso no mercado de trabalho formal do Brasil e em especial do estado do Rio de Janeiro, que foi um dos mais impactados nesse processo.

Como foi apontado acima, após Macaé apresentar um dinamismo muito acima da média no 
mercado de trabalho formal, com a crise de 2014, o município foi um dos que mais perderam postos de trabalhos no Rio de Janeiro e no Brasil. Entre 2015 e 2017 o município perdeu mais de 30 mil empregos formais, dos quais recuperou cerca de 8 mil em 2018 e 2019.

Essa perda de empregos teve impacto no Quociente Locacional das atividades relacionadas com a extração de petróleo e gás natural. Conforme observado na Tabela 2 e sintetizado no Gráfico 2 a seguir, observa-se uma redução expressiva do QL das atividades 'Extração de petróleo e gás natural' e 'Atividades de serviços relacionados com a extração de petróleo e gás exceto a prospecção realizada por terceiros’ de 2002 para 2014, com leve recuperação em 2019.

Gráfico 2: Evolução do QL nas principais atividades relacionadas com Extração de Petróleo e Gás Natural (2002 - 2014 - 2019)

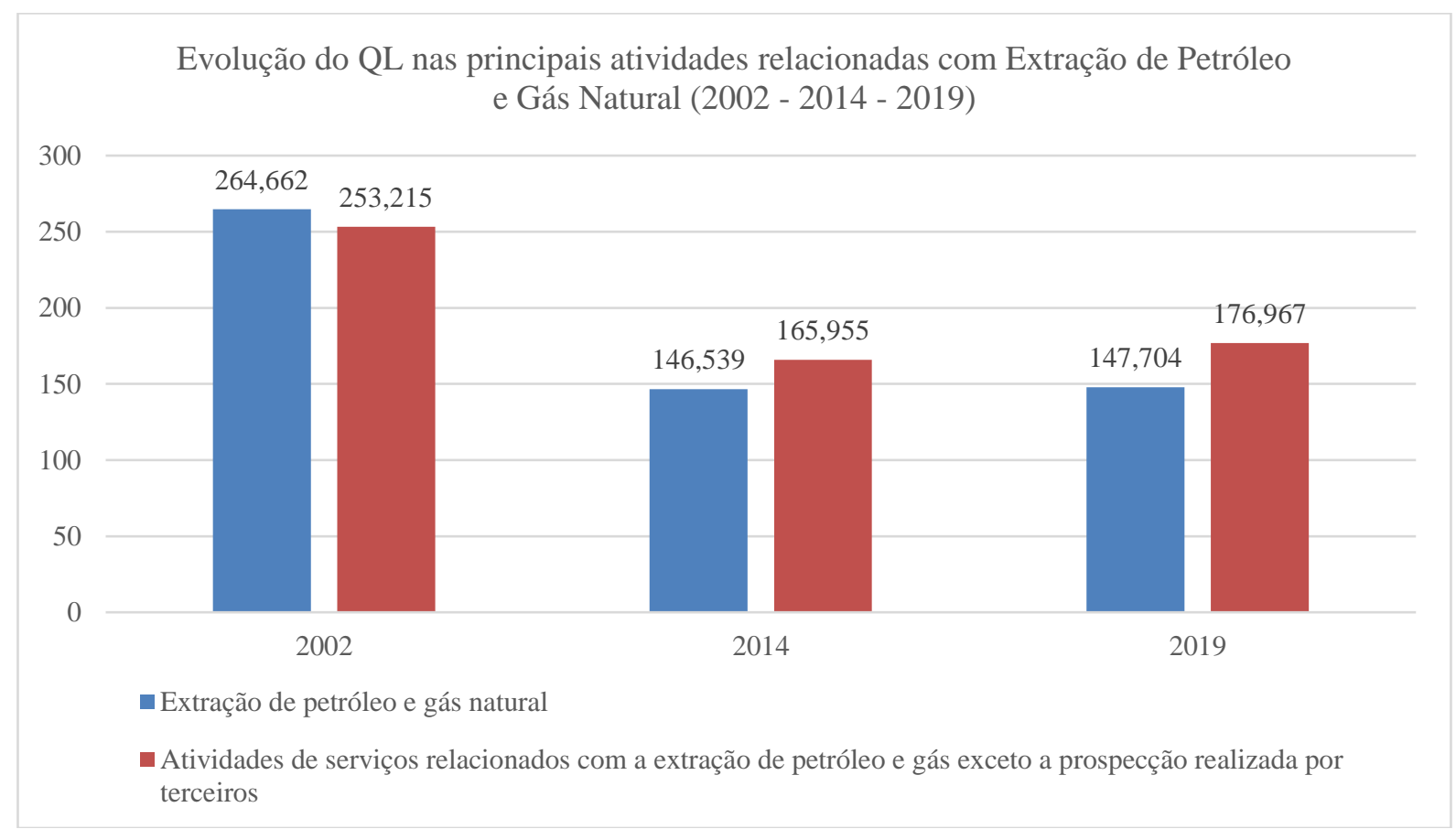

Fonte: RAIS (2021)

Ainda é cedo para avaliar como essa reestruturação da Petrobras e das outras petroleiras impactará o posicionamento do arranjo produtivo do petróleo e gás de Macaé na indústria petrolífera brasileira. Em 2019, embora se observe uma leve recuperação do QL das duas atividades, faz necessário uma análise da evolução das duas atividades na participação relativa do estoque de empregos formais no Brasil, a fim de se permitir um vislumbre das tendências que começam a ocorrer no país

Nesse sentido, conforme demonstrado no Gráfico 3, Macaé vem paulatinamente reduzindo sua participação no estoque de empregos da 'extração de petróleo e gás natural' das principais cidades produtoras do país. Até 2010, a participação de Macaé no estoque da atividade oscilou ao redor de 50\%, com o pico de $63 \%$ em 2005. O quadro começou a se alterar a partir de 2011, quando a participação do Rio de Janeiro, que já vinha crescendo desde 2007, se acelerou, de modo que em 2019, Macaé concentrou $38 \%$ dos empregos e o Rio de Janeiro passou a concentrar $17 \%$ do estoque (em 2007, esse 
índice era de 2,5\%). A crise a partir de 2014 não teve um impacto direto na participação de Macaé, pois as perdas foram setoriais e não locais. Na verdade, o que se pode concluir é que existe um movimento de paulatina mudança derivada da exploração do pré sal na Bacia de Santos, que ainda em fase de desenvolvimento, já superou a produção da Bacia de Campos. Isso tende a beneficiar o Rio de Janeiro, que fica no core geográfico da costa da Bacia de Santos, além, é claro, de sediar as principais operadoras.

Gráfico 3: Evolução do da Participação da Atividade ‘Extração de Petróleo e Gás’ (2002 a 2019)

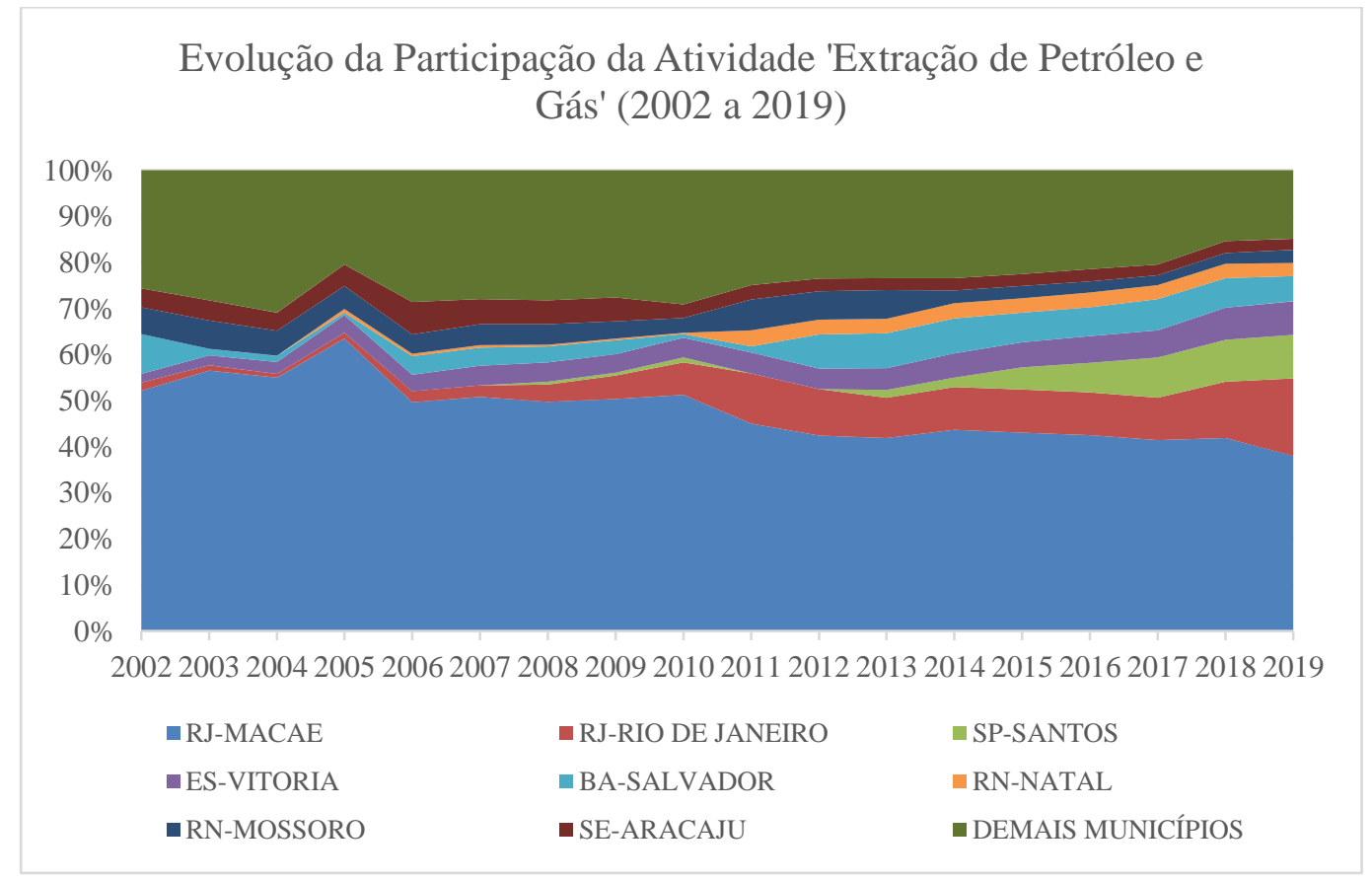

Fonte: RAIS (2021)

Uma evolução discretamente distinta aconteceu nas atividades de apoio à extração de petróleo e gás natural (ver Gráfico 4). Ao longo de quase todo o período em análise, a participação de Macaé oscilou ao redor de 50\%, sem evidência consistente de redução dessa participação. Em 2019, Macaé representou $45 \%$ das atividades de apoio (o pico foi 54\% em 2013), mas deve-se considerar o aumento da participação de Rio das Ostras, que passou a contar com mais de 7\% do estoque. Considerando as relações de proximidade, o arranjo continuaria, assim, a concentrar 52\% dos empregos nessas atividades. O Rio de Janeiro, por outro lado, manteve oscilou em torno de $15 \%$ ao longo de quase todo o período. A exceção foi entre 2006 e 2009, em que o Rio de Janeiro passou a concentrar entre $29 \%$ e $43 \%$ do estoque. Não é possível afirmar com certeza sem maiores estudos sobre as razões dessa inflexão, mas esses foram também os anos de descoberta do pré-sal na Bacia de Santos, o que permite a hipótese de que tenha havido alguma relação entre esse evento e o salto nos empregos dessas 
atividades no Rio de Janeiro ${ }^{15}$.

Gráfico 4: Evolução do da Participação da Atividade 'Serviços de Apoio à Extração de Petróleo e Gás' (2002 a 2019)

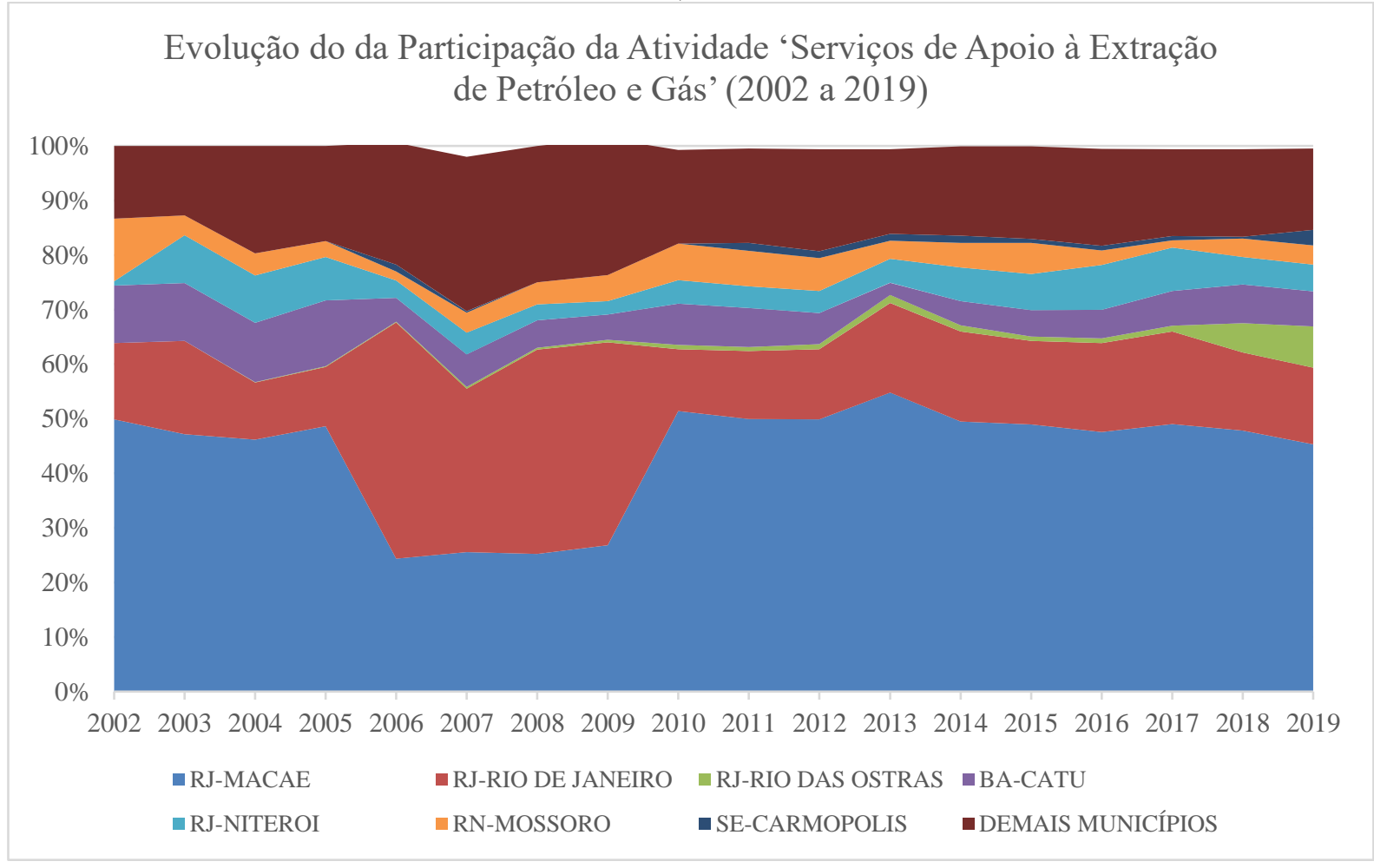

Fonte: RAIS (2021)

Vê-se que o arranjo produtivo, apesar da tendência de desconcentração das atividades de extração mineral em Macaé e seu entorno, que são operadas por um pequeno número de grandes empresas, incluindo as petroleiras, não apresenta evidências de que terá reduzida, de forma significativa, o seu importante papel de suporte territorial da produção petrolífera offshore.

A fim de se buscar uma melhor compreensão desse complexo cenário, faz-se importante analisar o impacto da crise em outros indicadores.

\subsection{Os impactos nas receitas municipais e na arrecadação de royalties e participações especiais}

Conforme mencionado, com a consolidação do enclave do petróleo e gás da Bacia de Campos em Macaé e com a Lei No. 9.478/1997, a chamada Lei do Petróleo, a 'economia dos royalties' passou a beneficiar diversos municípios, especialmente os confrontantes com as jazidas de petróleo em altomar.

${ }^{15}$ Considerando que em 2005, o estoque total no Brasil foi de 9.692 empregos formais, número que saltou em 2006 para 27.910 empregos, a maior parte contratada no Rio de Janeiro que saltou de 1.054 empregos em 2005 para 12.017 em 2006. 
A Lei do Petróleo marcou a abertura do setor para a exploração da iniciativa privada (Regime de Concessões). No Regime de Concessões, o Estado outorga às empresas petrolíferas o direito de realizar as atividades de exploração e produção (E\&P) em uma estipulada área ofertada ou licitada, por um tempo definido, sob o seu próprio risco. E, em caso de sucesso na exploração, a empresa adquire a propriedade do óleo extraído, bastando apenas compensar o Estado com os devidos pagamentos de royalties e participações especiais.

Os royalties representam compensação financeira devida pelos concessionários ao proprietário da área onde ocorre a atividade de E\&P a partir do início da produção comercial de cada campo. A participação especial, por sua vez, corresponde à compensação financeira extraordinária devida apenas nos casos de grande volume de produção ou de grande rentabilidade.

Essas receitas beneficiaram diversos municípios, com destaque para Campos dos Goytacazes e Macaé, na região Norte Fluminense, conforme se observa no Gráfico 5.

Gráfico 5: Evolução das Receitas de Royalties e Participações Especiais (em valor Real - corrigidos pelo IGP-DI) nos municípios de Campos dos Goytacazes e Macaé (1999 a 2020)

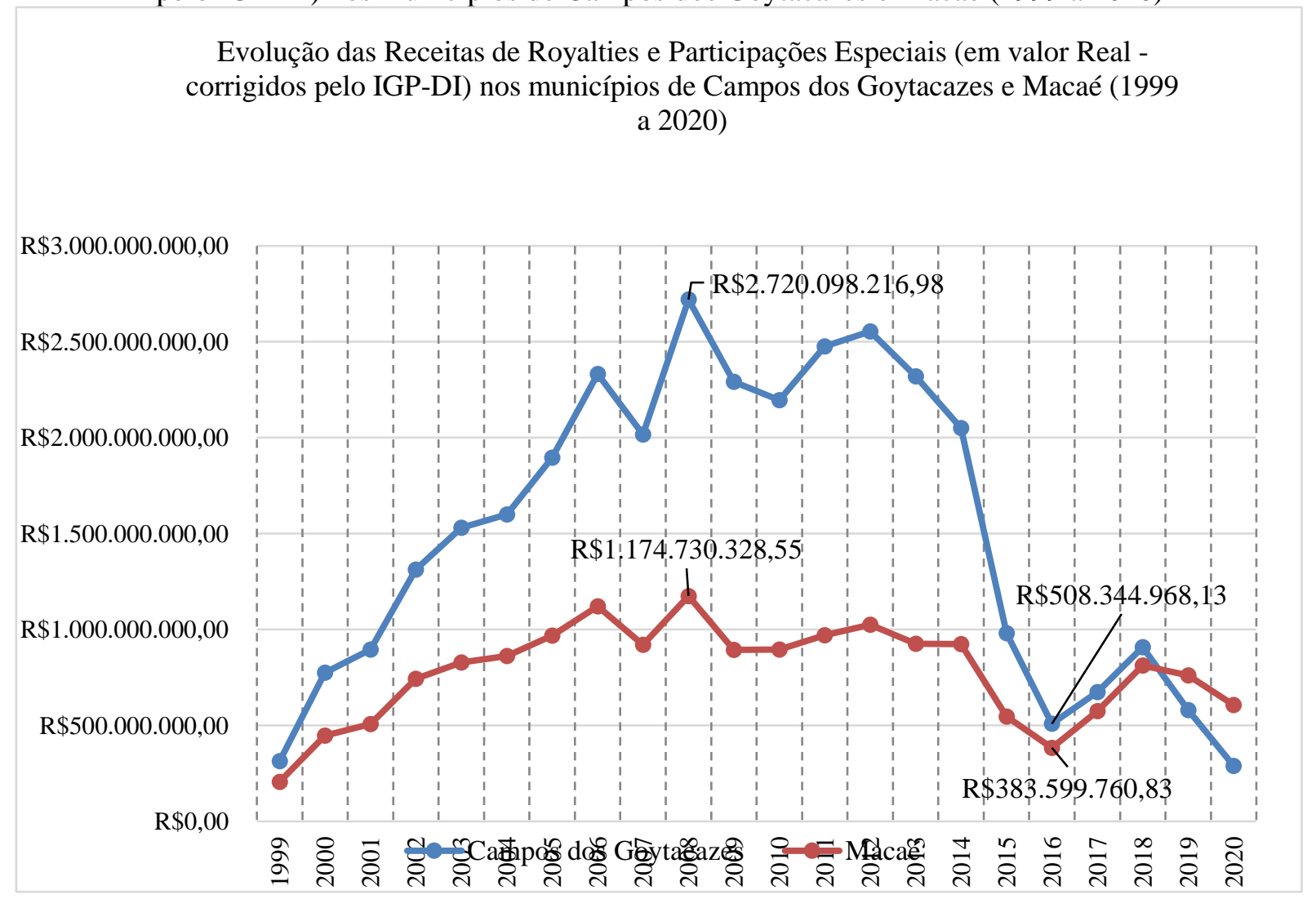

Fonte: Inforoyalties (2021)

As receitas cresceram de forma acelerada, com leve oscilação em 2007, até 2008, ano da crise 
do subprime americano, quando o município de Campos dos Goytacazes recebe R $\$$ 2,7 bilhões e o de Macaé, R\$ 1,17 bilhões. Em 2009 e 2010, há uma queda da arrecadação, mas a partir de 2011, observase uma leve recuperação até o ano de 2012, quando então passam a apresentar um forte declínio até 2016, quando Campos passa a receber 18,7\% da receita de 2008 e Macaé, 32,6\%. Conforme mencionado, essa perda de arrecadação, a exemplo da perda de empregos formais, deve-se ao deslocamento dos investimentos da Petrobras para o pré-sal na Bacia de Santos, relegando a Bacia de Campos a segundo plano, e aos efeitos do contrachoque do petróleo de 2014, que atuou na redução drástica das receitas do petrorrentismo. Em 2017 e 2018, influenciados pela recuperação do preço do petróleo no mercado internacional e pela alta do dólar, observa-se uma recuperação das receitas dos dois municípios, mas em 2019 e 2020 essas receitas voltam a cair. Cabe destacar que, a partir de 2019, pela primeira vez, Macaé passa a receber mais royalties e participações especiais do que Campos dos Goytacazes.

Assim como impactaram as receitas de royalties e participações especiais, esses dois fatores também impactaram a receita tributária ${ }^{16}$ do município de Macaé, base do APL de petróleo e gás natural, em especial sua principal fonte de arrecadação, o Imposto sobre Serviços (ISS). Conforme mostrado no Gráfico 6, embora se observe um aumento na arrecadação do Imposto Predial e Territorial Urbano (IPTU), demonstrando um claro esforço fiscal do município, o ISS interrompe uma sequência de crescimento em 2015 e segue em queda até 2018, com leve recuperação em 2019.

\footnotetext{
${ }^{16}$ A receita tributária corresponde ao esforço realizado pelo ente federativo municipal em arrecadar tributos de forma direta, acrescido do Imposto de Renda, não se levando em consideração quaisquer outras transferências.
} 
Gráfico 6: Evolução das Receitas Tributárias em Macaé (2014 a 2019)

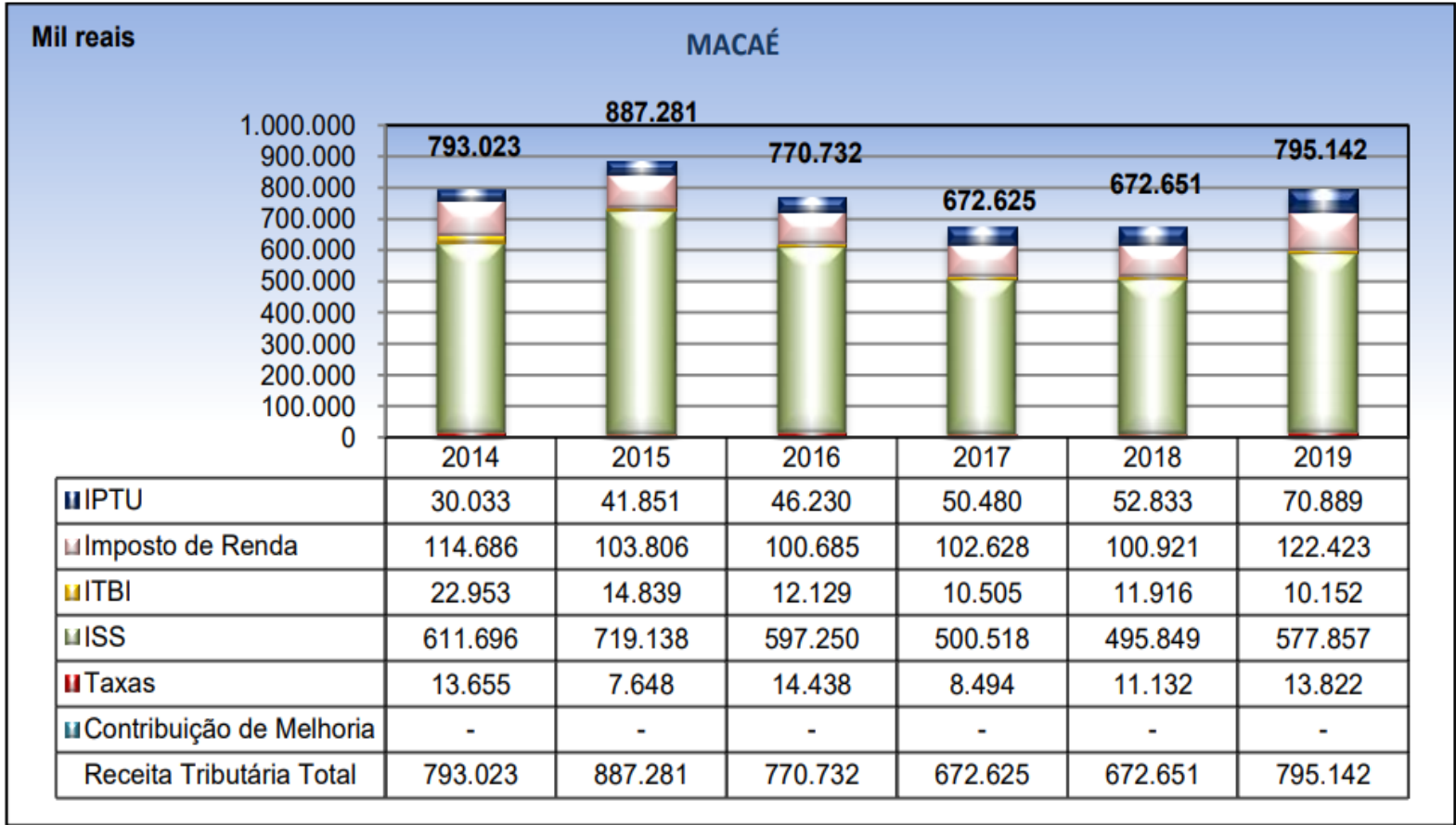

Fonte: TCE (2021)

Essa queda de arrecadação acabou por impactar negativamente outros indicadores, inclusive o 'Indicador do comprometimento da receita corrente com a máquina administrativa', que mede o nível de comprometimento do município com o funcionamento da máquina administrativa, utilizando-se recursos provenientes das receitas correntes (TCE, 2021). As despesas correntes destinam-se à manutenção dos serviços prestados à população, inclusive despesas de pessoal, mais aquelas destinadas a atender a obras de conservação e adaptação de bens móveis, necessárias à operacionalização dos órgãos públicos.

\subsection{Os impactos nos estabelecimentos e nos estoques de empregos formais nas atividades relacionadas com a extração de petróleo e gás natural}

No recorte temporal analisado, conforme observado no Gráfico 7, após uma sequência de 12 anos de criação de novos estabelecimentos, de 2002 a 2014, a partir de 2015, com a crise do contrachoque do petróleo, o Município de Macaé passa a apresentar declínio no número de estabelecimentos, quando até 2019, o município perde 526 estabelecimentos. 
Gráfico 7: Evolução do Número Total de Estabelecimentos - Macaé (2002 a 2019)

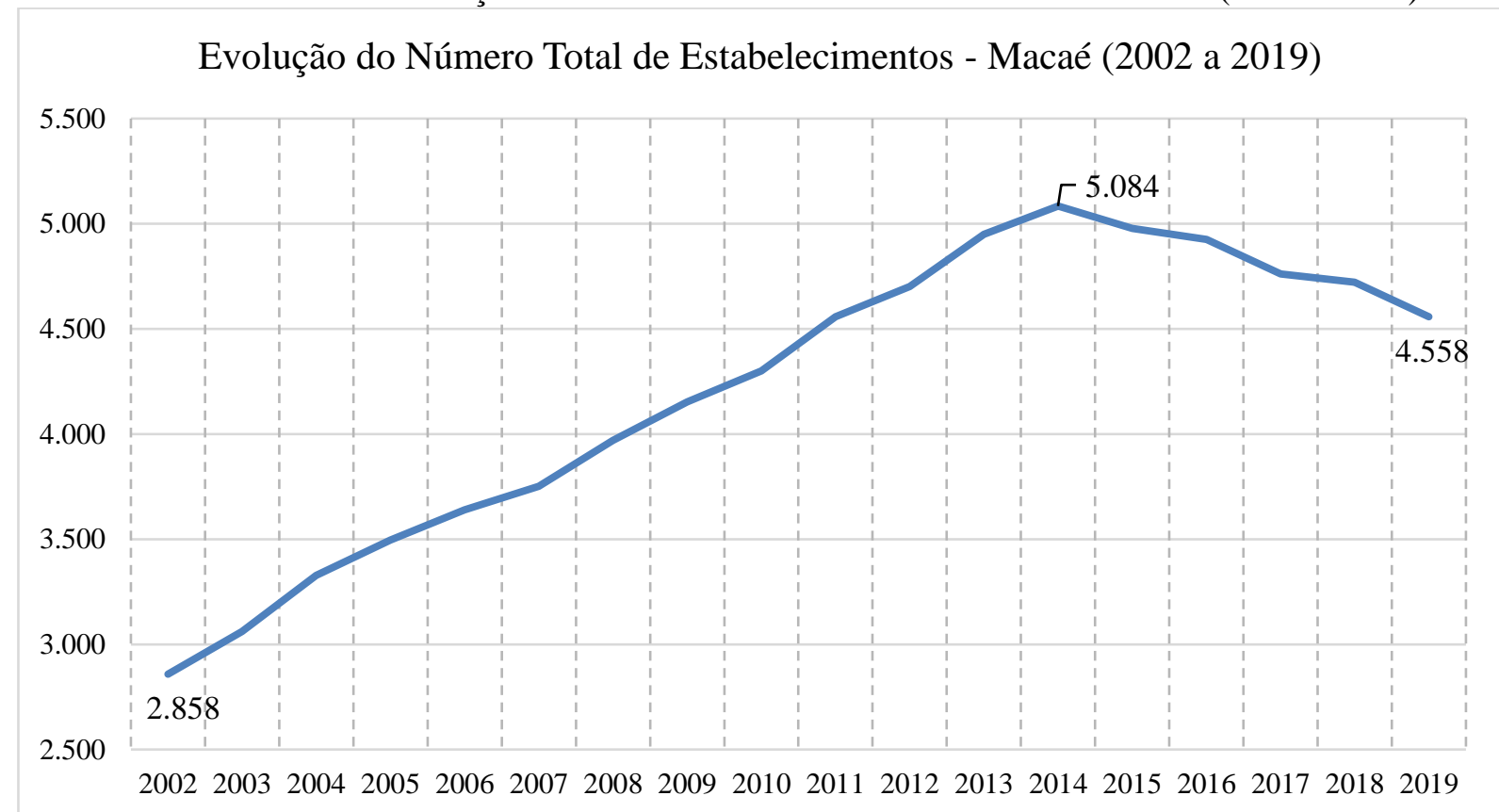

Fonte: RAIS (2021)

Esse declínio do número de estabelecimentos é fortemente influenciado pelo declínio do número de estabelecimentos nas atividades relacionadas com a extração do petróleo, conforme mostrado no Gráfico 8 a seguir. A atividade 'Serviços Relacionados com a Extração de Petróleo' perdeu 15 estabelecimentos de 2016 a 2019. E a atividade 'Extração de Petróleo e Gás Natural' se manteve estável, uma vez que é formado por poucas grandes empresas. Obviamente, em função da capacidade de arrasto, outros setores também são fortemente impactados pela diminuição do dinamismo dessas atividades. 
Gráfico 8: Evolução do Número de Estabelecimentos nas Atividades relacionadas com a Extração do Petróleo - CNAE 95 Grupo - Macaé (2002 a 2019)

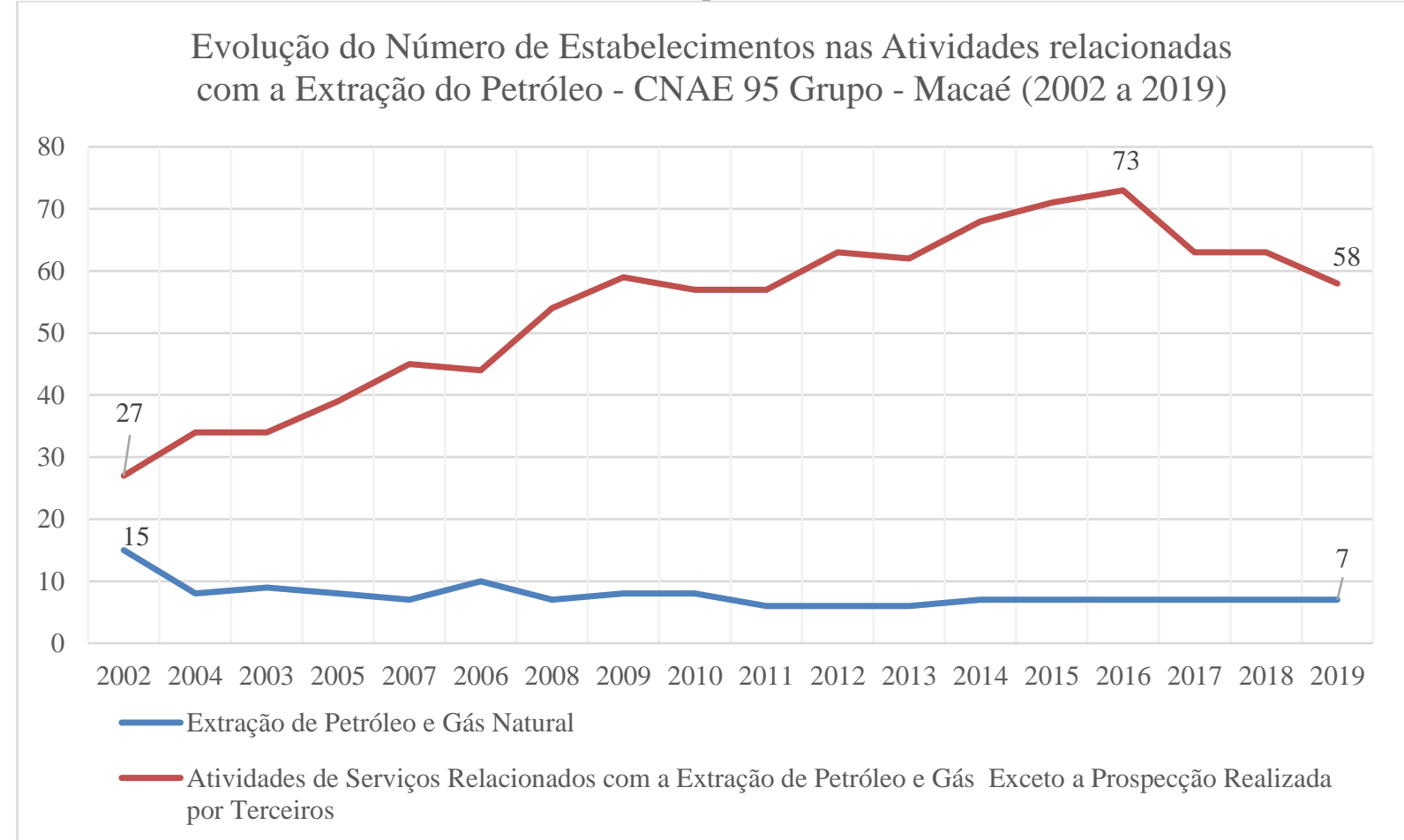

Fonte: RAIS (2021)

Os impactos da crise nessas atividades ficam mais evidentes quando se faz a análise da evolução dos empregos formais nessas atividades. De acordo com o Gráfico 9, a atividade 'Extração de Petróleo e Gás Natural' gerou empregos de forma crescente de 2002 a 2010, quando sentiu os impactos da crise do subprime americano e eliminou postos de trabalho. Voltou a gerar empregos, num ritmo mais lento, a partir de 2012, mas em 2013 voltou a eliminar empregos. A atividade perdeu 6.704 empregos formais de 2013 a 2017. Mas, com o arrefecimento da crise, voltou a gerar 1.771 empregos de 2017 a 2019.

A atividade 'Serviços Relacionados com a Extração de Petróleo' não sentiu os impactos da crise do subprime americano e seguiu gerando empregos até 2013. A partir deste ano perdeu 5.356 empregos formais de até 2018, quando voltou a gerar novos empregos, ganhou 125 de 2018 a 2019.

A atividade 'Administração do Estado e da Política Econômica Social' foi inserida nesse gráfico não por estar relacionada com a Extração do Petróleo, mas para se ratificar o impacto da crise no 'Indicador do comprometimento da receita corrente com a máquina administrativa', uma vez que houve redução de receitas e crescimento do número de empregos formais na atividade. Os empregos dessa atividade cresceram acentuadamente até 2010 e, a partir desse ano, mantiveram-se estáveis, com pequenas variações, até 2019. 
Gráfico 9: Evolução do Estoque de Empregos Formais nas Atividades relacionadas com a Extração do Petróleo - CNAE 95 Grupo - Macaé (2002 a 2019)

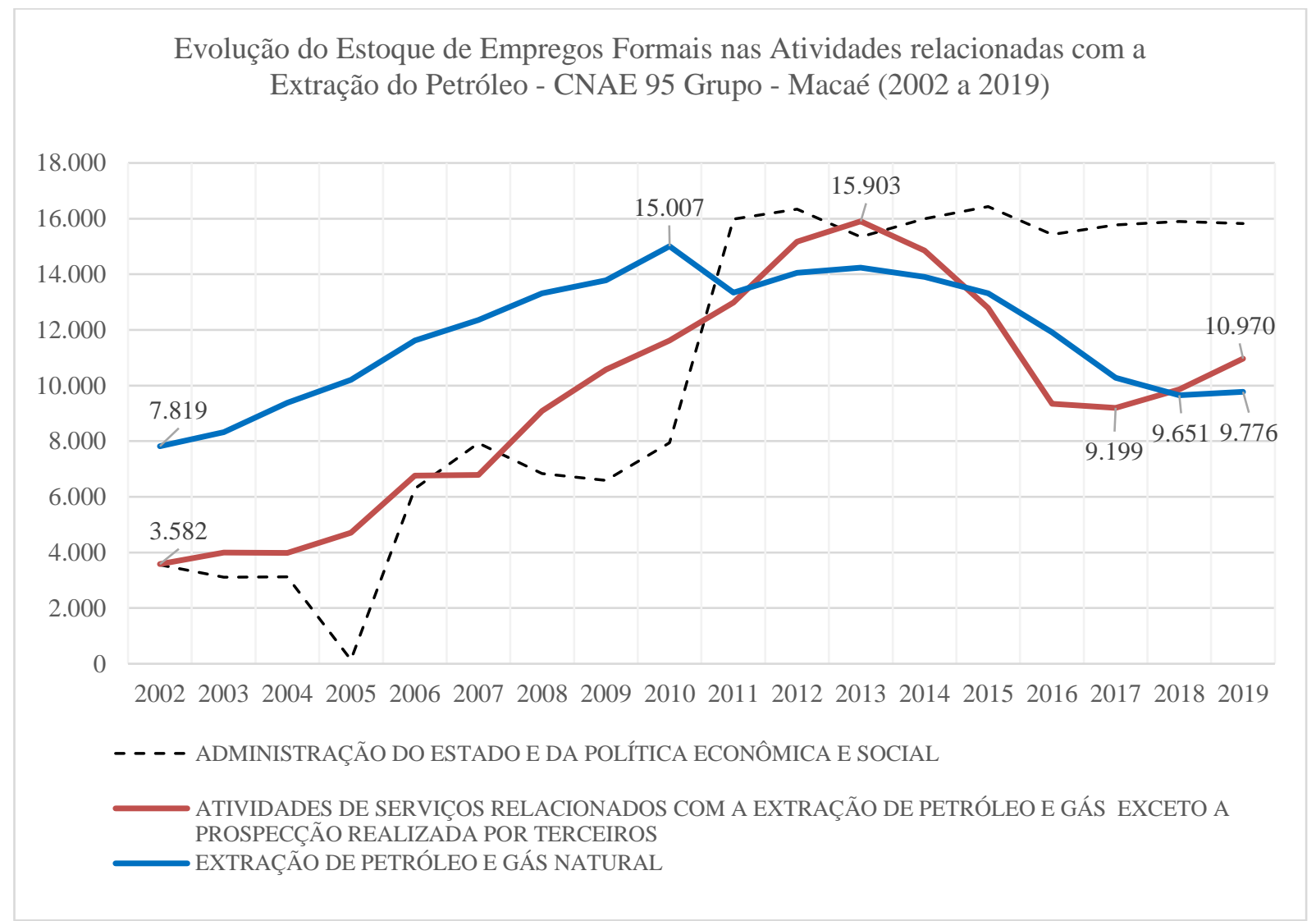

Fonte: RAIS (2021)

Analisando-se a evolução do estoque de empregos por porte do estabelecimento nesses setores, conforme Gráficos 10 e 11 a seguir, observa-se que as grandes empresas foram as que passaram por um processo de reestruturação mais profundo. Conforme mencionado anteriormente, na Atividade 'Extração de Petróleo e Gás Natural', há a predominância absoluta das grandes empresas em virtude da necessidade de grandes investimentos. As grandes empresas dessa atividade eliminaram 5.148 empregos formais de 2010 a 2017, mas criaram 121 de 2017 a 2019. 
Gráfico 10: Evolução do Estoque de Empregos por Porte dos Estabelecimentos na Atividade Extração de Petróleo e Gás Natural - Macaé (2002 a 2019)

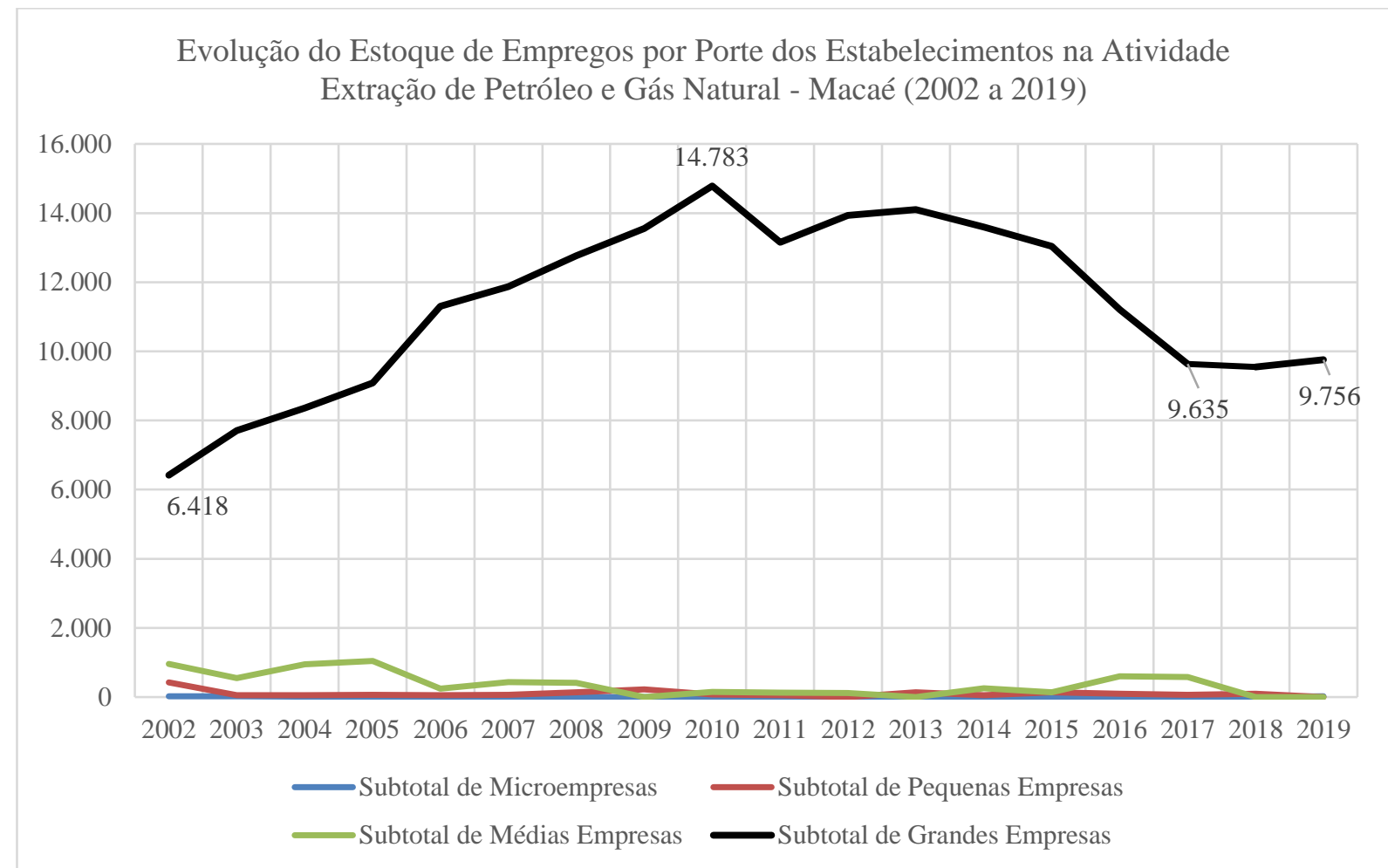

Fonte: RAIS (2021)

Na Atividade 'Serviços Relacionados com a Extração de Petróleo e Gás exceto a Prospecção realizada por Terceiros' (Gráfico 11), a predominância é de grandes, mas há uma mais expressiva presença de médias empresas em virtude da menor necessidade de investimentos. As grandes empresas dessa atividade, que criaram empregos ininterruptamente, de 2002 a 2013 chegando ao estoque de 11.111 empregos, também passaram por um profundo processo de reestruturação e eliminaram 7.119 empregos formais de 2013 a 2016, porém criaram 1.250 de 2016 a 2019. As médias empresas, após um declínio após a crise do subprime americano, apresentou crescimento acelerado de 2011 a 2015, porém eliminaram 1.263 empregos formais de 2015 a 2017, mas criaram 738 de 2017 a 2019. 
Gráfico 11: Evolução do Estoque de Empregos por Porte dos Estabelecimentos na Atividade Serviços Relacionados com a Extração de Petróleo e Gás exceto a Prospecção realizada por Terceiros - Macaé (2002 a 2019)

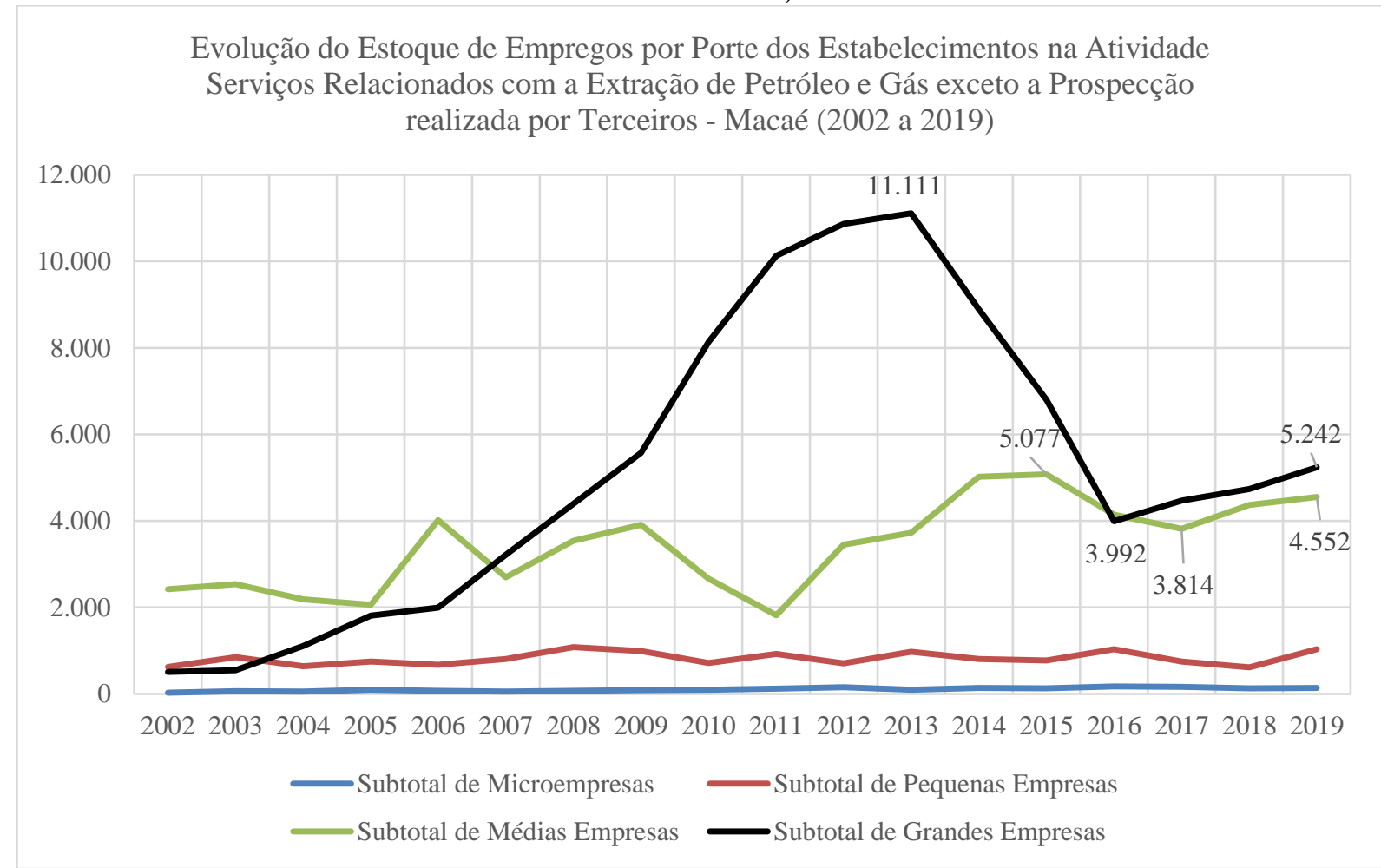

Fonte: RAIS (2021)

\subsection{Os impactos na Escolaridade, na Remuneração dos empregos e nas Ocupações nas atividades relacionadas com a extração de petróleo e gás natural}

Nesse processo de reestruturação das empresas das atividades relacionadas com a atividade de petróleo e gás natural, conforme se observa nos Gráficos 12 e 13, o nível de escolaridade que sofreu maior impacto foi o 'Médio completo e Superior incompleto'. Na Atividade Extração de Petróleo e Gás, de 2010 a 2012, esse nível de escolaridade perdeu 6.435 empregos, e o nível 'Superior completo' ganhou 5.403, numa inversão abrupta, em dois anos, de valorização do profissional de nível superior. No entanto, de 2012 a 2019, com os impactos da crise, o nível de escolaridade 'Superior completo' perdeu 5.528 empregos. O nível 'Médio completo e Superior incompleto' perdeu 969 empregos de 2012 a 2018, mas ganhou 2.372 empregos em 2019, observando-se com uma reversão do fenômeno observado nos anos 2010 a 2012. 
Gráfico 12: Evolução do Estoque de Empregos por Faixa de Escolaridade na Atividade Extração de Petróleo e Gás - Macaé (2002 a 2019)

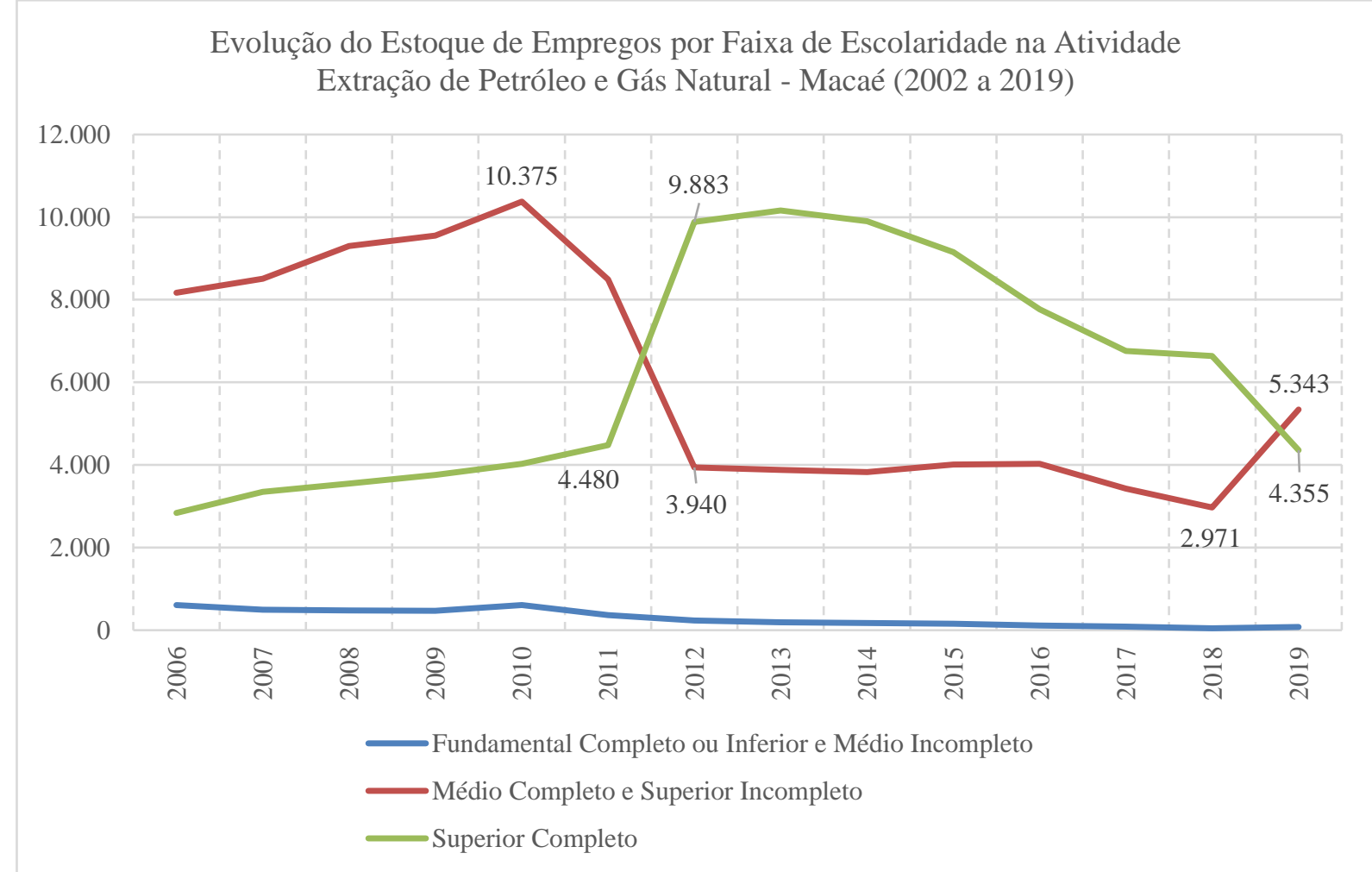

Fonte: RAIS (2021)

$\mathrm{Na}$ atividade 'Serviços relacionados', esse fenômeno não foi observado. A faixa 'Médio completo e Superior incompleto’ perdeu 4.657 empregos de 2013 a 2016. A partir de 2017, inicia-se um processo de leve recuperação. A faixa ‘Superior completo’ perdeu 1.239 empregos de 2013 a 2016 e também iniciou leve recuperação em 2017. A faixa 'Fundamental completo ou inferior e Médio incompleto' apresentou declínio em todo o período analisado, deixando clara a importância da escolaridade para a empregabilidade na atividade. 
Gráfico 13: Evolução do Estoque de Empregos por Faixa de Escolaridade na Atividade Serviços Relacionados com a Extração de Petróleo e Gás exceto a Prospecção realizada por Terceiros - Macaé (2002 a 2019)

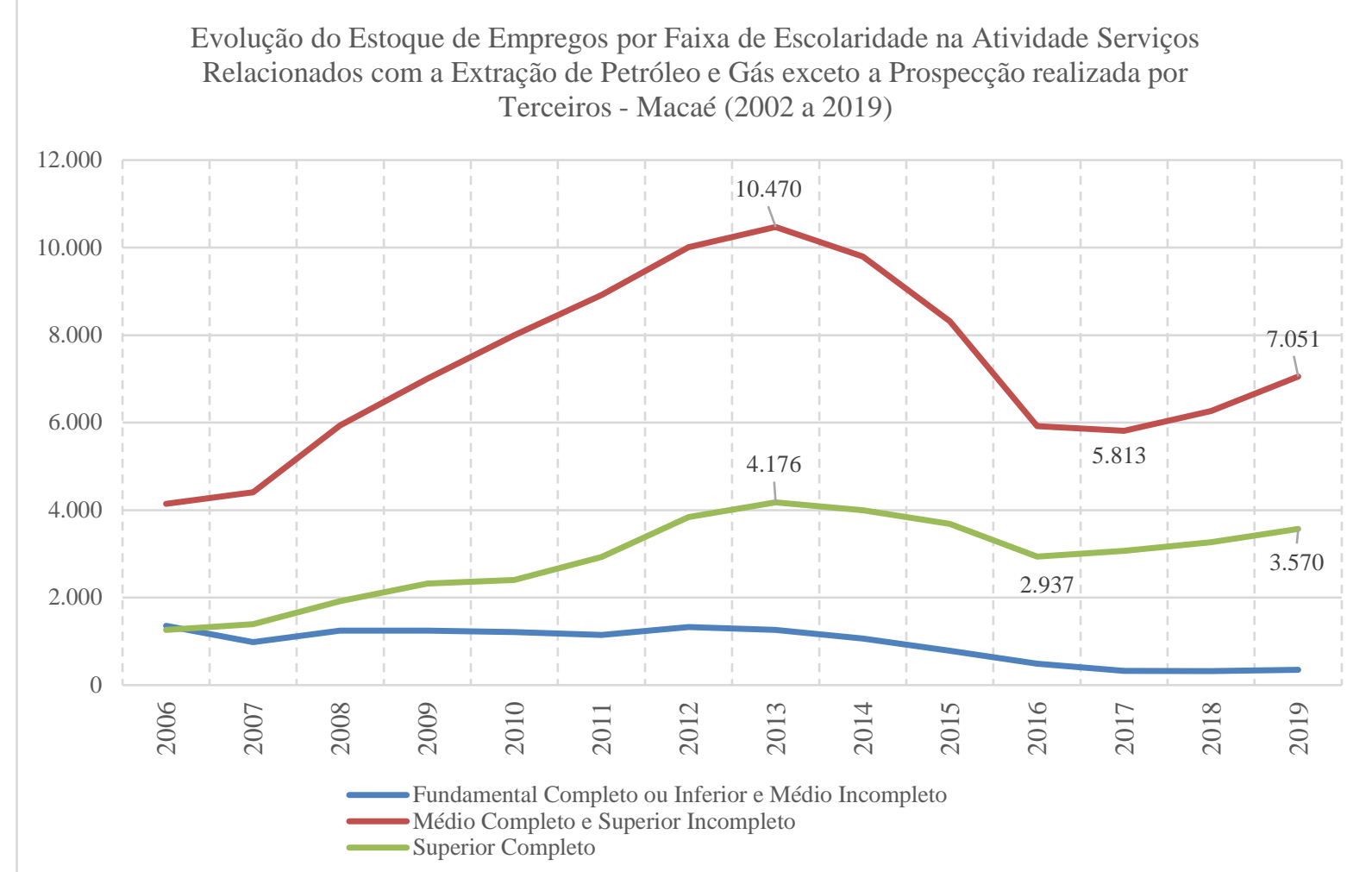

Fonte: RAIS (2021)

Quando se faz a análise do estoque de empregos por faixa de remuneração nas atividades relacionadas com a extração do petróleo (Gráficos 14 e 15), observa-se que no setor 'extração de petróleo e gás natural', a eliminação de empregos ocorreu majoritariamente nas faixas de maiores salários. A faixa 'Mais de 20 Salários Mínimos (SM)', despois de um crescimento sustentado de 2002 a 2014, com a crise, perdeu 3.573 empregos de 2014 a 2017 e recuperou 287 até 2019 . A faixa 'De 10 a 20 SM' perdeu 1.857 empregos de 2010 a 2019. 
Gráfico 14: Evolução do Estoque de Empregos por Faixa de Remuneração na Atividade Extração de Petróleo e Gás - Macaé (2002 a 2019)

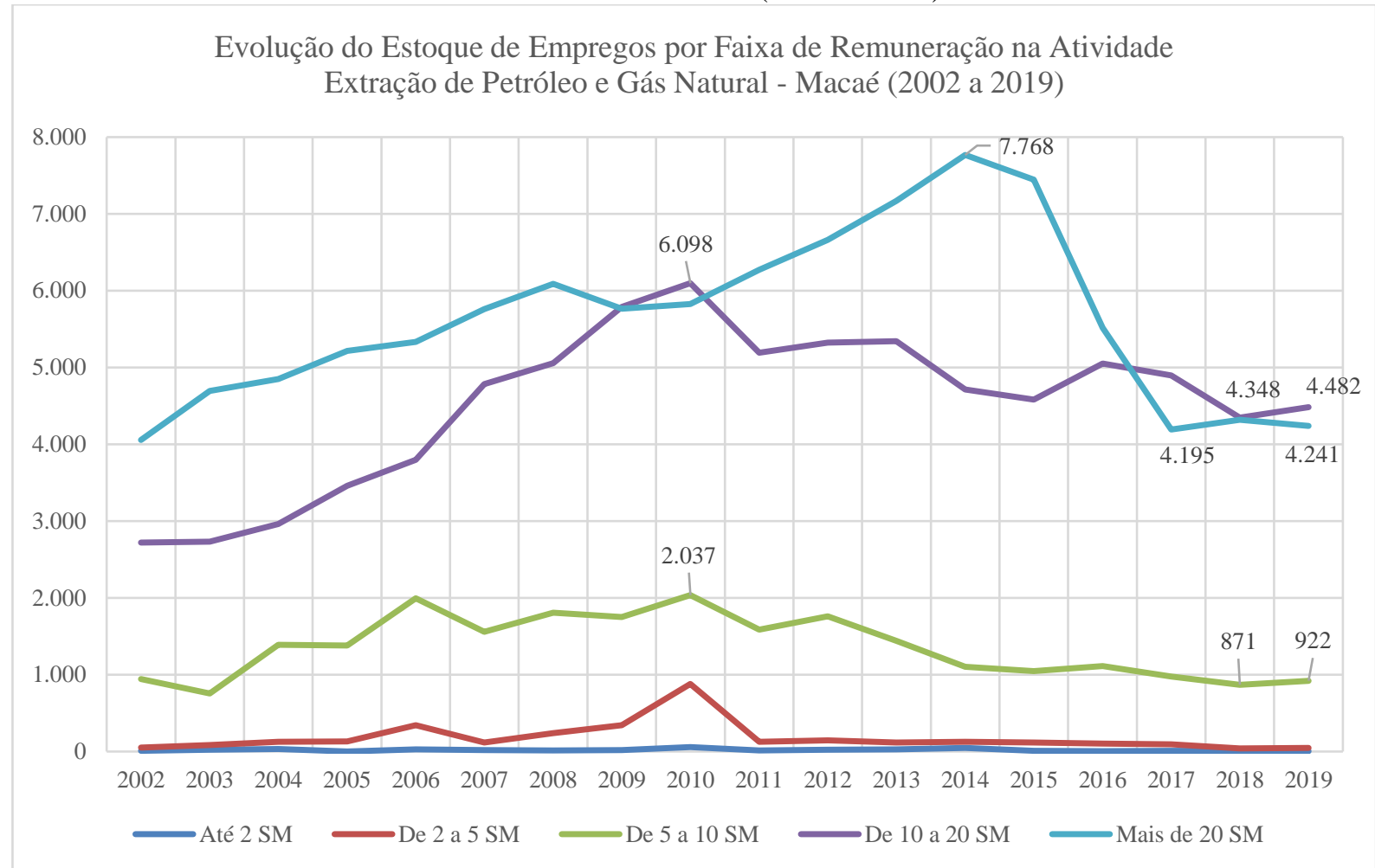

Fonte: RAIS (2021)

$\mathrm{Na}$ atividade 'Serviços relacionados', observa-se a partir de 2014 a eliminação de empregos em todas as faixas de remuneração. Mas as faixas que mais perderam empregos, de 2013 a 2016, foram a 'De 5 a 10 SM' com a eliminação de 2.367 empregos e a 'De 10 a 20 SM' com 1.739 empregos perdidos. 
Gráfico 15: Evolução do Estoque de Empregos por Faixa de Remuneração na Atividade Serviços Relacionados com a Extração de Petróleo e Gás exceto a Prospecção realizada por Terceiros - Macaé (2002 a 2019)

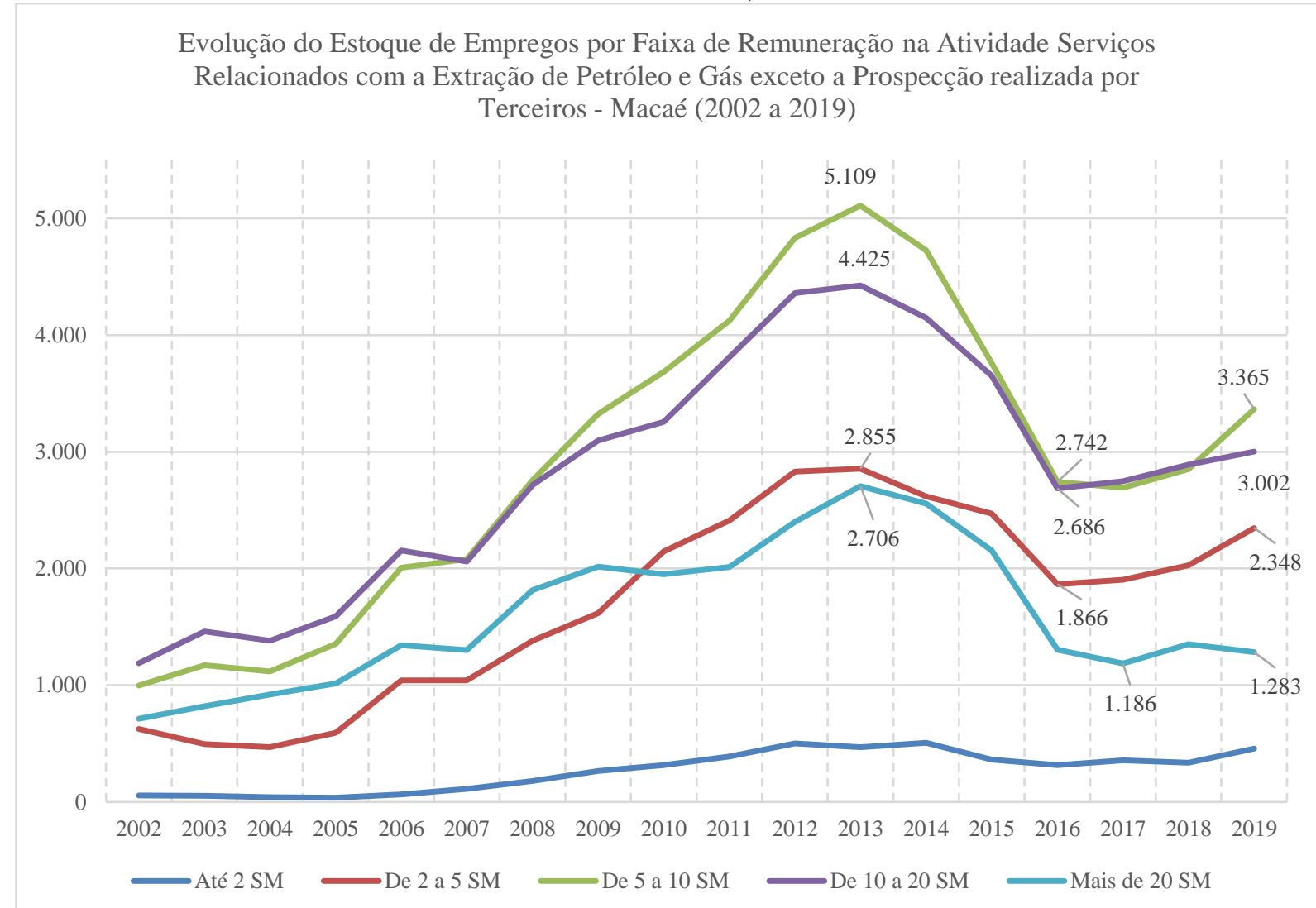

Fonte: RAIS (2021)

Por fim, as ocupações que mais perderam empregos, conforme se observa na Tabela 4, foram ‘Técnico Mecânico', com 1.690 empregos eliminados e 'Operador de exploração de petróleo', com 1.445 empregos. Essa análise ratifica as análises anteriores, quando se observou que a faixa de escolaridade mais impactada com a crise e com a reestruturação das empresas foi a 'Médio completo e Superior incompleto', e que as faixas de remuneração mais impactadas foram as mais elevadas 'De 5 a 10 SM', 'De 10 a 20 SM' e 'Mais de 20 SM'. 
Tabela 4: Evolução do número de empregos por Ocupações - Macaé (2013 a 2019)

\begin{tabular}{|c|c|c|c|c|c|c|c|c|}
\hline CBO Ocupação 2002 & 2013 & 2014 & 2015 & 2016 & 2017 & 2018 & 2019 & $\begin{array}{c}\text { Variação } \\
\text { no } \\
\text { Estoque }\end{array}$ \\
\hline $\begin{array}{l}\text { Operador de exploração de } \\
\text { petróleo }\end{array}$ & 3.451 & 3.402 & 3.138 & 2.648 & 2.166 & 2.065 & 2.006 & -1.445 \\
\hline Técnico mecânico & 3.289 & 3.282 & 2.637 & 1.673 & 1.593 & 1.553 & 1.599 & -1.690 \\
\hline Tecnico em segurança no trabalho & 1.140 & 1.158 & 1.157 & 982 & 931 & 978 & 1.048 & -92 \\
\hline Técnico em instrumentação & 113 & 131 & 445 & 872 & 824 & 832 & 837 & 706 \\
\hline Técnico de manutenção elétrica & 91 & 92 & 415 & 857 & 774 & 747 & 763 & 671 \\
\hline Plataformista (petróleo) & 1.363 & 1.160 & 1.058 & 764 & 770 & 759 & 756 & -607 \\
\hline $\begin{array}{l}\text { Engenheiro químico (petróleo e } \\
\text { borracha) }\end{array}$ & 651 & 613 & 645 & 663 & 572 & 599 & 645 & 32 \\
\hline $\begin{array}{l}\text { Sondador (poços de petróleo e } \\
\text { gás) }\end{array}$ & 1.023 & 962 & 790 & 597 & 541 & 543 & 637 & -325 \\
\hline Assistente administrativo & 922 & 873 & 735 & 557 & 437 & 405 & 471 & -402 \\
\hline Engenheiro mecânico industria & 947 & 903 & 739 & 429 & 383 & 411 & 444 & -459 \\
\hline
\end{tabular}

Fonte: RAIS (2021)

\section{CONSIDERAÇÕES FINAIS}

O arranjo produtivo de petróleo e gás natural formado em Macaé foi um dos principais vértices das transformações urbanas e regionais do eixo norte do interior fluminense, de modo que funcionou nas últimas 4 décadas como um sorvedouro populacional a partir da formidável geração de empregos formais. A partir da concentração das atividades de extração de petróleo e gás natural e das atividades de apoio, formou-se no município um pool de atividades com elevado nível de especialização locacional, pagadoras de salários mais altos e com exigências de competências técnicas que demandavam treinamento específico do sistema educacional público e privado.

Além disso, em conjunto com os municípios do entorno, confrontantes com a Bacia de Campos, Macaé se beneficiou da renda petrolífera que irrigou de forma extraordinária os orçamentos municipais. Como ocorreu em quase todos os municípios da região, tal abundância foi permeada por escândalos de corrupção e foi acompanhada pelo fortalecimento das relações clientelísticas que usavam dos empregos públicos não estáveis como forma de cooptação. Não obstante, tais recursos possibilitaram também o atendimento às crescentes demandas sociais por maiores e melhores serviços públicos, que tiveram inegável expansão no período, refletido pelo aumento do emprego no setor público da economia. 
O contrachoque de 2014, no entanto, teve um impacto profundo nessa dinâmica, trazendo uma inflexão negativa no mercado de trabalho local e regional, de modo que Macaé teve papel de liderança, juntamente com Campos dos Goytacazes, nas perdas verificadas nos últimos anos no interior fluminense. Os efeitos mais severos foram justamente nos empregos de maiores exigências de treinamento técnico especializado de nível médio e superior, e que também eram os que pagavam maiores salários. A pequena recuperação verificada a partir de 2018, entretanto, sinaliza o aproveitamento da oportunidade de muitas empresas em pressionar para baixo a folha de pagamento, por meio da substituição dos profissionais de maior tempo e salários nas empresas e a recontratação, dos mesmos profissionais ou não, para o exercício das mesmas funções com menores remunerações.

No entanto, como a crise foi generalizada, as perdas de Macaé não representaram menor centralidade do arranjo produtivo no conjunto das atividades de exploração e produção de petróleo e gás em relação a outros arranjos. O QL das duas atividades motrizes em Macaé diminuiu de 2002 a 2014, mas teve leve ascensão em 2019 em comparação com 2014, quando a economia ainda estava em pleno emprego. O que se tem verificado como tendência é o aumento da participação do município do Rio de Janeiro na extração de petróleo e gás natural, em virtude da posição estratégica da cidade na Bacia de Santos. Em relação ao entorno regional, tem se verificado, inclusive, clara distinção de Macaé em relação aos municípios mais dependentes das rendas petrolíferas. Apesar dos efeitos também severos no orçamento municipal, não se observou em Macaé a crise fiscal profunda verificada, por exemplo, em Campos dos Goytacazes. Trata-se da evidenciação da distinção entre a economia do petróleo e a economia dos royalties, que garante ao município maior resiliência às vicissitudes que assolam o setor e o país nos últimos anos.

Ainda assim, existem uma série de incertezas com relação à evolução futura do arranjo produtivo de petróleo e gás natural em Macaé. A questão mais imediata é qual será o papel do município com as mudanças territoriais da exploração e produção de petróleo e gás natural, que já se centraliza nas produtivas jazidas da Bacia de Santos e tende a favorecer o Rio de Janeiro. Com efeito, esse processo depende principalmente de três fatores.

Em primeiro lugar, depende da estratégia da Petrobras nos próximos anos com relação ao seu próprio portfólio na Bacia de Campos e sua relação com a estrutura que vem se desenvolvendo na Bacia de Santos. É improvável, por razões de custos e perdas de ativos intangíveis, que haja um esvaziamento do arranjo produtivo em Macaé, que deve se recolocar como um dos vértices a apoiar a produção na mais longínqua bacia ao sul. Mas possivelmente o município terá que abandonar o ufanista título auto concedido de "a capital do petróleo brasileiro". 
Em segundo lugar, a evolução (ou involução) dos marcos regulatórios e da política brasileira para a indústria de petróleo e gás natural nos próximos anos será determinante para a definição do lugar do arranjo produtivo no setor. Nos últimos anos, verifica-se a opção pela alienação de parte importante dos investimentos realizados pela Petrobras, que vem perdendo o caráter de empresa de petróleo integrada e, por consequência, tende a se tornar mais vulnerável às flutuações dos preços internacionais do petróleo. Essa opção, fruto de certo liberalismo primário e ingênuo que tomou conta da forma de pensar de parte das classes dirigentes do país, também tem significado menor preocupação por constituir capacidades tecnológicas locais. A despeito da profundidade como essa opção tem ocorrido nos últimos anos, não é a primeira vez que isso ocorre no Brasil. Dependendo da conjuntura política e da formação da agenda pública para o setor, não é impossível a ocorrência de nova inflexão no futuro, o que poderá ter efeitos positivos no arranjo produtivo.

Finalmente, associada ao fator precedente, existe a incerteza sobre os efeitos da reestruturação produtiva em curso no mundo com relação à matriz energética. Em vários países, em particular na União Europeia, deflagrou-se processos de substituição de automóveis de motor a combustão, por automóveis elétricos ou, pelo menos, híbridos, o que causará impacto na demanda internacional por petróleo. Essa mudança tecnológica pode tornar obsoleta a produção de petróleo, que apesar de continuar sendo uma commodity fundamental para a indústria, em particular como matéria prima de vários polímeros, pode deixar de ter a centralidade que possui atualmente. Nesse caso, o posicionamento energético do Brasil será fundamental. Há de se pensar se a estratégia surgida nos últimos anos de incentivo às termelétricas a gás natural ganhará importância ou não. Esse certamente é um tema para se acompanhar com pesquisas mais aprofundadas. 


\section{REFERÊNCIAS}

AGÊNCIA NACIONAL DO PETRÓLEO, GÁS NATURAL E BIOCOMBUSTÍVEIS. Superintendência de Desenvolvimento e Produção. Boletim da Produção de Petróleo e Gás Natural. Boletim da Produção de Petróleo e Gás Natural, Rio de Janeiro, n. 125, p. 1-40, 28 fev. 2021. Disponível em: https://www.gov.br/anp/pt-br/centrais-de-conteudo/publicacoes/boletinsanp/bmp/2021/2021-01-boletim.pdf. Acesso em: 9 mar. 2021.

AZEVEDO, L. C. SILVA NETO, R. Instabilidade no cenário socioeconômico e político no Brasil a partir de 2014: contrachoque do petróleo mudanças no marco regulatório e operação Lava Jato. Cadernos do Desenvolvimento Fluminense. n19. p.11-42. jul - dez 2020. Disponível em: https://www.e-publicacoes.uerj.br/index.php/cdf/article/view/59048/38347.

BRITTO, J.; VARGAS, M. O APL de Petróleo e Gás de Macaé in: MATOS, M. ; BORIN, E. ; CASSIOLATO, J.E. Uma década de evolução dos Arranjos Produtivos Locais, E-Paper, Rio de Janeiro, 2015.

CRESPO, N. E Campos dos Goytacazes perde a corrida do petróleo. PIQUET, R. (org.) Petróleo, royalties e região. Rio de Janeiro: Garamond, 2003, p. 239-256.

DIAS, R. S. Instituições e desenvolvimento territorial: um estudo a partir do caso do arranjo produtivo de petróleo e gás natural localizado em Macaé-Brasil. Eure - Revista Latinoamericana de Estudios Urbano Regionales. Santiago, Volume 39, Número 116, jan./2013, p. 141-171.

DIAS, R. S. Expansão e crise no mercado de trabalho formal fluminense entre 1985 e 2019. Cadernos do desenvolvimento fluminense. Rio de Janeiro, $\mathrm{n}^{\circ}$ 19, 2020, p. 92-126.

FAURÉ, Y. Macaé: internalizar as oportunidades do petróleo e diversificar a economia municipal. FAURÉ, Y. HASENCLEVER, L. (Orgs.) O desenvolvimento local no Estado do Rio de Janeiro: estudos avançados nas realidades municipais. Rio de Janeiro: E-papers, 2005, p. 215-322.

HASENCLEVER, L. MENDES, H. CAVALIERE, H. Especialización en recursos naturales y empleo en Brasil: El caso del petróleo en Río de Janeiro. Red Sud Americana de Economía Aplicada, Serie Documentos de Base del Reporte Recursos Naturales y Desarrollo 2015-2016, estudio país n 3 . Disponível em: https://obpetro.com.br/wp-content/uploads/2020/07/EP-3.-Especializacion-en-RRNNy-empleo-en-Brasil-el-caso-del-Petroleo-en-ERJ.pdf acessado em 10 de julho de 2021.

INFOROYALTIES. Programa de Pós-graduação em Planejamento Regional e Gestão de Cidades. Universidade Cândido Mendes. Disponível em: http://inforoyalties.ucam-campos.br/. Acesso em: 27 jul. 2021.

LASTRES, M. H.; CASSIOLATO, J. E. "Novas Políticas na Era do conhecimento: O foco em Arranjos produtivos e Inovativos Locais". RedeSist, IE/UFRJ, 2003, site: www.ie.ufrj.br/redesist consulta em dezembro de 2011.

LENCIONI, S. Urbanização difusa e a constituição de megarregiões. O caso de São Paulo-Rio de Janeiro. E-metrópolis. Rio de Janeiro, nº 22, 2015, p. 6-15.

MONIÉ, F. Petróleo, industrialização e reorganização do espaço regional. PIQUET, R. (org.) Petróleo, royalties e região. Rio de Janeiro: Garamond, 2003, p. 257-285.

PESSANHA, R. M. A ampliação da fronteira de exploração petrolífera no Brasil é parte da geopolítica da energia: oportunidades e riscos de inserção global em meio às novas territorialidades regionais e ao desafio da abundância na economia dos royalties no Estado do Rio de Janeiro. Espaço e economia. Rio de Janeiro, $n^{\circ}$ 6, 2015. 
PESSANHA, R. M. A relação transescalar e multidimensional "Petróleo-Porto" como produtora de novas territorialidades. 2017. 560 f. Tese (Programa de Pós-graduação em Políticas Públicas e Formação Humana) - Universidade do Estado do Rio de Janeiro, [S. l.], 2017.

RAIS. Relação Anual de Informações Sociais. Disponível em: 〈http://pdet.mte.gov.br/rais〉. Acesso em: 15 jul. 2021.

ROSENDO, R. CARVALHO, A. M. Formação econômica da Região Norte Fluminense. In: PESSANHA, Roberto Moraes; SILVA NETO, Romeu. Economia e desenvolvimento no Norte Fluminense. Campos dos Goytacazes: WTC, 2004.

SILVA, R. C. R. S. da; BRITTO, J. O Aglomerado de Empresas Atuantes no Segmento Off-Shore de Macaé: impactos da política de subcontratação da Petrobras na bacia de Campos. Revista Brasileira de Inovação, Campinas, SP, v. 8, n. 1, p. 121-166, 2009. DOI: 10.20396/rbi.v8i1.8648977. Disponível em: https://periodicos.sbu.unicamp.br/ojs/index.php/rbi/article/view/8648977. Acesso em: 8 set. 2021.

TRIBUNAL DE CONTAS DO ESTADO DO RIO DE JANEIRO (TCE-RJ). Estudos Socioeconômicos Municípios do Estado do Rio de Janeiro - Macaé 2020. Rio de Janeiro: TCE-RJ. 2020. 140p.

VEBLEN, T. A teoria da classe ociosa: um estudo econômico das instituições. São Paulo: Pioneira Editora, 1965. 